This is the peer reviewed version of the following article: Salisu, AA, Swaray, R, Adediran, IA. Can urban coffee consumption help predict U.S. inflation?. Journal of Forecasting. 2019, which has been published in final form at https://doi.org/10.1002/for.2589. This article may be used for non-commercial purposes in accordance With Wiley Terms and Conditions for self-archiving.

\title{
Can urban coffee consumption help predict U.S. inflation?
}

\author{
Afees A. Salisu ${ }^{\mathrm{a}, \mathrm{b}}$, Raymond Swaray ${ }^{\mathrm{c}, *}$, Idris A. Adediran ${ }^{\mathrm{d}, \mathrm{e}}$
}

aDepartment for Management of Science and Technology Development, Ton Duc Thang University, Ho Chi Minh City, Vietnam.

bFaculty of Business Administration, Ton Duc Thang University, Ho Chi Minh City, Vietnam. Email: afees.adebare.salisu@tdt.edu.vn;

Tel: $+234(0) 8034711769$.

cEconomics Subject Group, University of Hull Business, University of Hull, Cottingham Road,

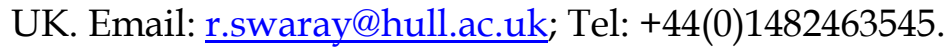

d Centre for Econometric \& Allied Research, University of Ibadan, Nigeria.

e Department of Economics, Obafemi Awolowo University, Nigeria.

Email: meetadediran@gmail.com; Tel: +234(0)7032240914.

*Corresponding Author:

Email: $\underline{\text { r.swaray@hull.ac.uk }}$ 


\title{
Can urban coffee consumption help predict US inflation?
}

\begin{abstract}
Motivated by the importance of coffee to Americans and the significance of the coffee subsector to the US economy, we pursue three notable innovations. First, we augment the traditional Phillips curve model with the coffee price as a predictor, and show that the resulting model outperforms the traditional variant in both in-sample and out-of-sample predictability of US inflation. Second, we demonstrate the need to account for the inherent statistical features of predictors such as persistence, endogeneity and conditional heteroskedasticity effects when dealing with US inflation. Consequently, we offer robust illustrations to show that the choice of estimator matters for improved US inflation forecasts. Third, the proposed augmented Phillips curve also outperforms time-series models such as ARIMA and ARFIMA for both in-sample and out-of-sample forecasts. Our results show that augmenting the traditional Phillips curve with the urban coffee price will produce better forecast results for US inflation only when the statistical effects are captured in the estimation process. Our results are robust to alternative measures of inflation, different data frequencies, higher-order moments, multiple data samples and multiple forecast horizons.
\end{abstract}

JEL Classification: C53, E31, E37

Keywords: USA, Phillips curve, Coffee price, Inflation forecasts, Forecast evaluation 


\section{Introduction}

Over the past decades, the link between prices of commodities (fuel and non-fuel) and macroeconomic/financial indicators such as economic activity, inflation, interest rates, exchange rate, stock price and money has been widely established in the literature (see, for example, Boughton and Branson, 1988; Webb, 1988; Boughton et al., 1989; Baillie, 1989; Garner, 1989; Marquis and Cunningham, 1990; Cody and Mills, 1991; Sephton, 1991; Pecchenino, 1992; Blomberg and Harris, 1995; Furlong and Ingenito, 1996; Browne and Cronin, 2010; Ciner, 2011; Frankel, 2013). Equally, a number of studies have singled out the role of commodity prices as an indicator of consumer inflation (see Gilbert, 1990; Bloch et al., 2004; Kyrtsou and Labys, 2006; Richards and Pofahl, 2009; Ferrucci et al., 2010; Gómez et al., 2012; Chen et al. 2014; Kagraoka, 2015; Davidson et al., 2016; Gelos and Ustyugova, 2016). These studies are largely motivated by the implications of commodity prices for the effectiveness of policy decisions (especially monetary policy). Since commodity prices precede inflation, information about their variations can be exploited by monetary authorities in policy decisions. This conclusion is particularly valid for the USA, where the consumption of commodities is ranked the largest after China, and therefore inflation dynamics are more likely to be closely related to movements in commodity prices.

Studies on the commodity price-US inflation nexus tend to either use crude oil (a fuel commodity) or gold (a metal commodity which has historical links to the US dollar and other major currencies), or a broad index of commodity prices (see Mahdavi and Zhou, 1997; Hooker, 2002; Kilian, 2008; Edelstein and Kilian, 2009; Valcarcel and Wohar, 2013; Hoang et al., 2016; Salisu and Isah, 2018). So far, no study has examined the role of coffee alone in predicting US inflation. We argue that there are several motivations for this special consideration of coffee consumption in predicting inflation in the USA. First, statistics from the US Department of Agriculture show the USA as the largest single country consumer of coffee, importing about 2.5 million $60 \mathrm{~kg}$ bags of coffee beans in 
December 2017 (US Department of Agriculture, 2017). ${ }^{1}$ Unlike other commodities such as crude oil, of which the USA is a major producer, or gold, coffee is exclusively an import to the USA. Coffee as a beverage has gained increasing popularity among younger adults in the USA and Europe, and coffee-drinking has been linked to beneficial effects on health and longevity in newspaper reports. ${ }^{2}$ A report by the Financial Times (2018) attributes the recent growth in US coffee consumption to "café culture among millennial" coffee drinkers.

Second, at the micro level, coffee is the most widely consumed beverage by households in the USA. The Minister of Agriculture and Agri-Food Canada (2013) highlighted coffee as a daily staple beverage in the USA that is "consumed across all incomes, ages, genders and states" and considered as an "instant energy boost for those on-the-go" (p.2). A study by Mintel (2012) shows that 76\% of US consumers bought coffee produce to use at home. This reality has implications for inflation through the exchange rate pass-through. Thus, an unanticipated change in the coffee price could put pressure on consumer price inflation, given the high consumer demand nature of the US economy.

Third, US corporations dominate coffee retailing and marketing around the world. Five out of the top ten specialist coffee house chains in the world are US-registered firms. In particular, Starbucks Corporation (a Seattle-based firm) alone has sales revenue which was more than treble the revenue of the remaining nine combined in 2015 (Euromonitor International, 2016). ${ }^{3}$ It has never been easier to access a cup of coffee at home, in offices or in hotel rooms with new, improved coffee makers and coffee pod machines. ${ }^{4} \mathrm{~A}$ recent

\footnotetext{
${ }^{1}$ Note that the European Union as a trading block of 28 countries is the largest importer of coffee, importing average 3.84 million $60 \mathrm{~kg}$ bags per month in 2017.

${ }^{2}$ See the following articles in the New York Times: "More consensus on coffee's effect on health than you might think," May 11, 2015; “Coffee drinkers may live longer," July 2, 2018; "Coffee may tame the redness of rosacea," October 17, 2018.

${ }^{3}$ The top ten global coffee house chains in 2015 were Starbucks (USA), Costa Coffee (UK), McCafe (USA), Doutor Coffee Shop (Japan), Coffee Bean \& Tea Leaf (USA), Caffe Nero (UK), Tully's (USA), Ediya Espresso (South Korea), Caribou Coffee (USA), Gloria Jean's Coffees (Australia).

${ }^{4}$ Gassmann et al. (2014) questioned whether anyone would imagine ten years ago that coffee drinkers would buy Nespresso coffee capsules for $€ 80$ per kg.
} 
report by Euromonitor International estimates total global spending on coffee at $\$ 180-200$ billion per year, and US firms are at the forefront of consolidation and business model innovation in the worldwide coffee market. The global coffee industry has benefited from remarkable innovations in product, process and business models over the past decade, which mirror wider innovations in the USA and the world economy. In addition, the recent acquisition of UK-based Costa Coffee (the second largest coffee chain in the world) by Coca-Cola and an alliance established between Starbucks and Nestlé further exemplifies US firms' global dominance of the "new age of coffee everywhere" (Euromonitor International, 2018, p.1). In this new era of coffee, it is an "American firm" that has taken "café culture", which is essentially "Italian", to global consumers (Economist, 2016).

Fourth, coffee is a commodity which has a "single final use", namely as a "beverage", a unique characteristic which distinguishes it from other tradeable commodities. In addition, coffee "is not combined with any other input to produce the final good", though extracting the soluble component is amenable to a range of manufacturing methods (Maizels et al., 1997, p.143). Production of coffee beans is subject to exogenous supplyside shocks, and once produced the beans are not storable over prolonged periods without deterioration in quality or at high storage costs, which contributed to a breakdown in International Commodity Agreements (Gilbert, 1987, 1996; Swaray, 2007). Consequently, we posit that the coffee price (all-urban CPIfor coffee) in the USA is likely to hold predictive power for inflation in the USA, which calls for a rigorous empirical investigation.

Generally, the theoretical propositions for considering commodity prices in this light are situated around the Theory of Overshooting Commodity Prices, found in the works of Frankel (1986). The commodity markets reflect all available supply and demand shocks in the economy and these shocks (including shocks to aggregate demand, wealth, aggregate investment, technological innovation, harvest failures and labor shortages, 
among others) give room for unanticipated inflation arising from the market (see Malliaris, 2006). Consequently, in the event of such unanticipated inflation, when commodity prices rise, wholesalers and retailers of products respond swiftly by passing along a certain proportion of the price increase to consumers (see Richards et al., 2012). This feeds into general inflation to the extent that the markets interconnect.

In this paper, we examine the role of the coffee price in producing accurate inflation forecasts for the US economy. The theoretical basis for forecasting inflation is rooted in Phillips curve models (traditional and augmented variants). The traditional Phillips curve (TPC), justified from the post-Keynesian theory of demand-pull inflation, specifies a trade-off between inflation and the level of aggregate demand. This model has retained its relevance over the years for modelling inflation, whether as a single equation model or in a system of equations such as the Dynamic Stochastic General Equilibrium model and the macroeconometric model. Augmenting the TPC with the coffee price allows us to isolate coffee prices from the composite commodity price index, which might suppress the significance of the coffee price as an important driver of inflation in the basket of commodity prices. Lenten (2010) examined the accuracy of "headline" and "underlying" inflation forecasts in Australia in the face of claims from politicians that temporary shocks to prices of commodities such as "bananas and oil" are behind rising headline inflation forecasts. A recent study by Navamuel et al. (2017) used prices of tropical beverages (coffee, tea and cocoa) and other food commodities in a demand system to obtain cost-ofliving differentials between urban and rural areas in Spain. Tallman and Zaman (2017) drew on the standard Phillips curve framework to forecast services and goods subcomponents of US inflation separately, as emphasized by Peach et al. (2013). Their results show clear improvements in the accuracy of both point and density forecasts of inflation.

However, a number of endogeneity issues may arise in the estimation process, as commodity prices including the coffee price respond to both demand and supply shocks, 
and therefore the strict exogeneity assumption may not be appropriate. For instance, shocks to the coffee supply, climate change and ageing of farmers in the coffee-producing nations, among other factors, can affect the coffee price. Closely related to the endogeneity issue is the persistence effect, which is also a prominent feature of most commodity prices. This is usually expected as the effect of shocks on the commodity market tends to persist (see Narayan and Liu, 2011).

On this basis, we account for any inherent endogeneity bias and persistence effect in the predictive model for inflation. In this case, the choice of estimator may matter in the analysis. This is motivated by the findings of Lewellen (hereafter "LW"; 2004), who proposes an alternative estimator to Ordinary Least Squares (OLS) in the presence of endogeneity and persistence effects. The proposed estimator, described as the biasadjusted OLS estimator, is found to outperform the standard OLS in the presence of persistence and endogeneity. ${ }^{5}$

Another important feature of our data that may require special attention is the conditional heteroskedasticity effect, since we are dealing with high-frequency series. This special consideration is also motivated by the findings of Westerlund and Narayan (hereafter “WN"; 2012, 2015), who propose a Feasible Quasi Generalized Least Squares (FQGLS) estimator as an alternative to the LW estimator. Thus, in addition to the endogeneity and persistence effects captured in the bias-adjusted OLS estimator of LW (2004), the FQGLS estimator also accounts for the conditional heteroskedasticity effect. ${ }^{6}$ We thus subject both the traditional and augmented Phillips curve-based inflation models to these alternative estimators - that is, OLS, LW and WN - and the forecast performance of these estimators

${ }^{5}$ Another possibility that has been explored is the prospect that (commodity) prices are time varying (see Narayan and Sharma, 2018).

${ }^{6}$ A number of papers have recently employed the FQGLS estimator of WN $(2012,2015)$ to model and forecast financial and economic series such as stock returns (see, for example, Narayan and Gupta, 2015; Narayan and Sharma, 2014; Narayan and Bannigidadmath, 2015; Phan et al., 2015; Bannigidadmath and Narayan, 2016; Devpura et al., 2018); public expenditure (see Makin et al., 2014); and inflation (see Salisu and Isah, 2018). 
is comparatively evaluated. Thus, we are able to establish whether the choice of estimator matters for the inflation forecast.

More importantly, we test whether augmenting the TPC with the coffee price will enhance its inflation forecasts. For robustness purposes, the analyses are subjected to different measures of inflation, different frequencies, multiple data samples and multiple forecast horizons. For completeness, we also compare the forecast results of the theory-based inflation forecast models with time-series models such as the Autoregressive Integrated Moving Average (ARIMA) and the Fractionally Integrated version (ARFIMA). This is important in order to establish whether theory-based models will beat the benchmark time-series models, in the face of contrary evidence from a number of papers (see, for example, Atkeson and Ohanian, 2001; Stock and Watson, 2003, 2007, 2008; Canova, 2007; Ang et al., 2007).

The rest of the paper is structured as follows. Section 2 provides the basis for augmenting the Phillips curve-based inflation model with the coffee price. Section 3 presents the model set-up, including the forecast performance measures. Section 4 deals with data and preliminary analyses. In Section 5 we present and discuss the results, while Section 6 concludes the paper.

\section{Motivation for the augmented Phillips curve-based inflation model}

The conclusion of Stock and Watson (hereafter "SW"; 2009) that commodity prices do not improve TPC-based inflation forecasts has continued to generate debate in the literature and reinvigorated researchers' interest in formulating alternative methods of overturning the conclusion. There are two strands in this regard. The first strand involves the use of commodity price aggregates, as in SW (2009), but considers alternative methodologies in order to deal with issues of non-linearities and structural breaks (see Browne and Cronin, 2010; Ciner, 2011; Chen et al., 2014). The second strand attempts to isolate key components of the composite commodity price index, such as the oil price, gold price or coffee price, 
among others, and thereafter tests the significance of the individual components in the prediction of inflation (see, for example, Otero, 2001; Raju and Melo, 2003; Belke et al., 2012; Fernandez, 2014; Karlsson and Karlsson, 2016; Van Hoang et al., 2016; Sek, 2017; Salisu and Isah, 2018).

In the case of the first strand, using the VAR methodology on US data, Browne and Cronin (2010) find that equilibrium relationships exist between money, commodity prices and consumer prices (inflation); that both commodity and consumer prices are proportional to the money supply in the long run; and that commodity prices can predict future CPI inflation. Also, Ciner (2011) provides evidence for a long-term positive relation between commodity prices and inflation when frequency dependency (non-linear dynamics between the variables) is accounted for statistically. Further, Chen et al. (2014) find that world commodity price aggregates have predictive power for their CPI inflation, particularly once possible structural breaks are taken into account. Contrary to the findings of SW (1999 and others), Chen et al. (2014) show that the inflation model with commodity prices outperforms the random walk and autoregressive models.

The second strand of studies focuses on single-commodity price-inflation relationships, such as the strong link between gold and inflation found by Van Hoang et al. (2016) and similar results for the oil price and inflation (Salisu et al., 2017a, 2018; Sek, 2017; Salisu and Isah, 2018). For indexes of multiple commodities, Fernandez (2014) shows that commodities such as beverages (coffee), food (maize, rice and wheat) and minerals display bidirectional linear and non-linear feedback effects with the general price level. Further results from Gelos and Ustyugova (2016) suggest that economies with higher food shares in CPI baskets are more prone to experience sustained inflationary effects from commodity price shocks.

For the coffee price-inflation relationship, the first notable attempt can be attributed to the work of Edwards (1984), which isolates coffee prices from the basket of commodity 
prices to support the position of a positive relationship between the price of coffee, money creation and inflation in Colombia. Other related studies are Cuddington (1986), Kamas (1986), Musonda and Luvanda (1986), Bonnell et al. (1990), Bevan et al. (1992), Otero (2001), Raju and Melo (2003), Belke et al. (2012) and Karlsson and Karlsson (2016). Like Edwards, Raju and Melo (2003), for example, show that the coffee price has a positive effect on inflation in addition to real exchange rate appreciation in response to periods of coffee boom. Similarly, Karlsson and Karlsson (2016) reveal that the coffee price can serve as a predictor for consumer inflation. Given the foregoing, we are therefore motivated to extend the previous analyses of the coffee price-inflation nexus from the perspective of Phillips curve-based inflation models. The choice of the Phillips curve model is intended to draw our model closer to SW (2009), since the conclusion of the latter was based on the

chosen model. We also attempt to put paid to the issue of methodology in upturning SW's (2009) results by subjecting the theory-based inflation model to different estimation methods. As customary in theory-based forecasting, the forecast results from the Phillips curve are compared with those of time-series models in order to verify whether theory matters to produce accurate US inflation forecasts.

\section{The model and forecast evaluation}

\subsection{The model}

As previously noted, the underlying theory for the inflation forecasts rendered in this study follows the demand-based Phillips curve model, also described as the NewKeynesian Phillips curve framework. This variant of the Phillips curve allows us to evaluate the role of real economic activity inflation forecasts (where the industrial production index is used as a proxy for real economic activity to allow for high-frequency observations). Thus, a simple representation of the demand-based Phillips curve can be represented as

$$
\pi_{t}=\alpha+\beta(L) \pi_{t}+\lambda(L) y_{t}+\varepsilon_{t} ; \lambda>0
$$


where $\pi_{t}$ is represented as the $\log$ of the consumer price index; $y_{t}$ is the log of the industrial production index; and $L$ is a polynomial in the lag operator. Equation (1) is the backward-looking Phillips curve framework which has dominated the literature, where inflation is regressed on a constant, its own lagged values and lagged output (see, for example, Salisu et al., 2017a, 2018). A positive relation is hypothesized for the outputinflation nexus. An expansion in the consumer demand for goods and services will raise the general price level, ceteris paribus, through its money effect, which is the case of too much money chasing too few goods. In other words, Equation (1) can be described as demand-side inflation.

Also, in this paper we aim to understand whether commodity market shocks measured as changes to the coffee price will matter for the predictability of a Phillips curve-based US inflation forecast. This is in line with studies like Chen and Rogoff (2003) and Chen et al. (2014), which argue for the role of commodity prices as viable proxies for the supply side. The underlying intuition rests on the fact that global commodity prices affect domestic prices through their direct effects on production costs and real outputs, and indirectly result in domestic inflation through the exchange rate pass-through, especially in commodity-exporting economies (see Salisu et al., 2017b, and relevant papers cited therein).

Thus, we modify the predictive theoretical framework in Equation (1) to reflect the supply-side component of the specification using changes in the coffee price. This, in a way, captures the impact on US inflation of shocks to the coffee supply through climate change, coffee booms and ageing of farmers in the coffee-producing nations, among other factors. Thus, any potential mis-specification arising from ignoring supply-side inflation which may undermine the accuracy of US inflation forecasts is resolved. Nonetheless, any inherent bias resulting from the persistence and endogeneity of the coffee price is also captured in the estimation. Discussions relating to how the latter is achieved are presented in the next section. 
From the foregoing, we therefore respecify Equation (1) as follows:

$$
\pi_{t}=\alpha+\beta(L) \pi_{t}+\lambda(L) y_{t}+\gamma(L) p_{t}+\varepsilon_{t} ; \lambda>0 ; \gamma>0
$$

where $p_{t}$ is the $\log$ of coffee price obtained at period $t$. Similar to the output-inflation nexus, a positive relation is also hypothesized for the coffee price-inflation nexus. The intuition is that demand and supply shocks (e.g. shocks to aggregate demand, wealth, aggregate investment, technological innovation, harvest failures and labor shortages, among others) give room for unanticipated price changes; when commodity prices rise, wholesalers and retailers of products respond swiftly by passing along a certain proportion of the price increase to consumers, and this feeds into general inflation to the extent that the commodity and non-commodity markets interconnect. Subsequently, Equations (1) and (2) are described as the traditional and augmented Phillips curve-based inflation models, respectively.

\subsection{The LW (2004) and WN (2015) estimators}

LW (2004) seems to be the first attempt to deal with persistence and endogeneity in a predictive model. A simple representation of the underlying predictive model of the LW estimator for a single factor is given as:

$$
\pi_{t}=\alpha+\beta z_{t-1}+\gamma\left(z_{t}-\rho z_{t-1}\right)+\varepsilon_{t}
$$

where $\pi_{t}$ is as previously defined and $z_{t}$ is a potential predictor variable of $\pi_{t}$ which can be replaced by the single factor in the TPC. Equation (3) is a reparameterization of both 
persistence and endogeneity effects. ${ }^{7}$ Solving for $z_{t-1}$ above gives a bias-adjusted OLS estimator of $\beta$, defined in this paper as the LW estimator. ${ }^{8}$

$$
\beta_{a d j}=\beta-\gamma(\rho-1)
$$

The predictability of output in the inflation model is evaluated under the null hypothesis that $\beta_{a d j}=0$. Thus, output is considered a good predictor of inflation if the null hypothesis is rejected; otherwise, it is not. The additional term in Equation (3) - that is, $\gamma\left(z_{t}-\rho z_{t-1}\right)$ - is introduced to resolve any bias resulting from endogeneity and persistence effects, with their respective parameters denoted as $\gamma$ and $\rho$.

In econometrics, the problem of endogeneity bias is usually attributable to two reasons: the omission of important explanatory variables; and two-way causality between explanatory variables and the explained variable. Therefore, resolving such bias in the estimation is inevitable given the fact that inflation is influenced by several variables, albeit with varying contributions to its forecast performance. Moreover, in periods of improved macroeconomic stability, using inflation as a proxy may influence the level of real economic activity, including the demand and supply of coffee. However, such reverse causation is not reflected in the original equation as in (1), and that partly explains the need to adjust the equation appropriately to control for such endogeneity bias, as provided for in Equation (3). The results of the endogeneity bias tests in Table 4 in the next section confirm the inherent endogeneity effect in the predictive model, particularly with respect to inflation and the coffee price.

\footnotetext{
${ }^{7}$ Equation (3) results from a simple predictive model expressed as $\pi_{t}=\mu+\beta z_{t-1}+v_{t}$ and is based on the underlying assumptions that the persistence and endogeneity effects, respectively, follow the specifications as $z_{t}=\vartheta(1-\rho)+\rho z_{t-1}+e_{t}$ and $\hat{v}_{t}=\gamma \hat{e}_{t}+\varepsilon_{t}$. Equation (3) is obtained by reparameterizing the resulting equation after substituting the expressions for the two effects into the simple predictive model. Note that $\alpha=\mu+\gamma \vartheta(1-\rho)$. ${ }^{8}$ See LW (2004), WN $(2012,2015)$ and Narayan and Gupta (2015) for a detailed exposition of the underlying derivations required to resolve any bias arising from endogeneity and persistence in the predictive model.
} 
In addition to endogeneity and persistence effects, it may also be necessary to account for a conditional heteroskedasticity effect, particularly when dealing with high-frequency series. We employ the FQGLS estimator proposed by WN $(2012,2015)$, which involves pre-weighting Equation (3) in such a way as to exploit the information contained in the conditional heteroskedastic variance of the regression residuals, in order to generate more precise estimates. The estimation of the weighted predictive model by OLS is described as the FQGLS estimator and is given as:

$$
\beta_{F Q G L S}=\frac{\sum_{t=q_{m}+2}^{T} \hat{\tau}_{t}^{2} z_{t-1}^{d} \pi_{t}^{d}}{\sum_{t=q_{m}+2}^{T} \hat{\tau}_{t}^{2}\left(z_{t-1}^{d}\right)^{2}}
$$

where $\hat{\tau}_{t}=1 / \hat{\sigma}_{\varepsilon, t}$ is used in weighting all the data in the predictive model, $z_{t}^{d}=z_{t}-\sum_{s=2}^{T} z_{t} / T$ and $\pi_{t}^{d}=\pi_{t}-\sum_{s=2}^{T} \pi_{t} / T$.

Following the LW and WN approaches, we can respectively rewrite Equations (1) and (2) as follows:

$$
\begin{gathered}
\pi_{t}=\alpha_{y}+\beta_{y} y_{t-1}+\gamma_{y}\left(y_{t}-\rho_{y} y_{t-1}\right)+\varepsilon_{y, t} \\
\pi_{t}=\alpha_{p, y}+\beta_{y} y_{t-1}+\beta_{p} p_{t-1}+\gamma_{y}\left(y_{t}-\rho_{y} y_{t-1}\right)+\gamma_{p}\left(p_{t}-\rho_{p} p_{t-1}\right)+\varepsilon_{p, y, t}
\end{gathered}
$$

Equations (6) and (7) represent the LW and WN variants for the traditional and augmented Phillips curve models, respectively. Notwithstanding the various considerations in both equations, we also compare their forecast performance with the original Equations (1) and (2) estimated with OLS.

\subsection{Estimation and forecasting procedure}

The analyses in this paper are done in three stages. The first stage involves pre-testing of each of the variables for endogeneity, persistence and conditional heteroskedasticity effects to justify our methodological divergence. The second stage involves in-sample predictability and forecast evaluation. The former involves testing whether the predictors are statistically significant regardless of the choice of estimator, while the latter involves 
evaluating the forecasting power of the alternative estimators. The intention here is to establish two things. First, we test whether the choice of estimator matters for accurate US inflation forecasts; and second, we demonstrate that the augmented Phillips curve (APC) model will offer superior forecast performance relative to the traditional variant. Both the Root Mean Square Error (RMSE) and Mean Absolute Error (MAE) are used as forecast measures. In addition, the Campbell and Thompson (hereafter " $\mathrm{C}-\mathrm{T}^{\prime}$; 2008) test is also used as a complementary measure of forecast performance for RMSE and MAE. One additional advantage of using the C-T test lies in the fact that one is able to determine the model with better forecast performance at a glance, unlike RMSE and MAE, where at every point the statistics for the competing models will have to be compared before any meaningful conclusion can be drawn. The C-T test is described as the out-of-sample Rsquared $\left(O O S_{-} R\right)$ statistic. The $O O S_{-} R$ is given by $O O S_{-} R=1-\left(M \widehat{S} E_{1} / M \widehat{S} E_{0}\right)$, where $M \widehat{S} E_{1}$ and $M \widehat{S} E_{0}$ are the mean square error of the out-of-sample prediction from the unrestricted and restricted models, respectively. A positive value for the statistic - that is, $O O S_{-} R>0$ - suggests that the unrestricted model outperforms the restricted model.

Since it is hard to determine the equality of forecast accuracy between two competing models on the basis of the C-T test, we also employ the Diebold and Mariano (hereafter "D-M") test. In other words, the D-M test is used to test for the equality of forecast accuracy of two forecasts and is computed as:

$$
\text { D-M stat }=\frac{\bar{d}}{\sqrt{\frac{1}{T} V(d)}} \sim N(0,1)
$$

where $\bar{d}=\frac{1}{T} \sum_{t=1}^{T}\left[f\left(\varepsilon_{i t}\right)-f\left(\varepsilon_{j t}\right)\right]$ is the sample mean loss differential and $V(d)$ is the unconditional variance of $d$. The $\left\{\varepsilon_{i t}\right\}_{t=1}^{T}$ and $\left\{\varepsilon_{j t}\right\}_{t=1}^{T}$ are the forecast errors associated with the two forecasts, say $\left\{\hat{z}_{i t}\right\}_{t=1}^{T}$ and $\left\{\hat{z}_{j t}\right\}_{t=1}^{T}$, respectively. The $f\left(\varepsilon_{i t}\right)$ and $f\left(\varepsilon_{j t}\right)$ are the loss functions associated with these two forecasts, while $d_{t} \equiv f\left(\varepsilon_{i t}\right)-f\left(\varepsilon_{j t}\right)$ is the loss 
differential. The null hypothesis of equal forecast accuracy for two forecasts is that $E\left[d_{t}\right]=0$. There is relative equality between the two forecasts if the null hypothesis of the $\mathrm{D}-\mathrm{M}$ test is not rejected; otherwise, there is not.

The third stage involves out-of-sample forecast evaluation. We consider multiple insample periods using $50 \%$ and $75 \%$ of total observations for robustness checks. Also, the rolling window approach is adopted, as against the fixed parameter approach, in order to capture any underlying time-varying property of the coefficients of the Phillips curve. This consideration is motivated by the findings of studies such as Stock and Watson (1999), Atkeson and Ohanian (2001), Orphanides and Van Norden (2004), Ang et al. (2007), Canova (2007) and Riggi and Venditti (2015), suggesting that the parameters of the Phillips curve are unstable, which may affect the accuracy of inflation forecasts. More specifically, Canova (2007) finds that accounting for the time-varying parameter feature of the Phillips curve improves the forecast performance of the model.

As is customary, we also compare our models that rely on economic information (both traditional and augmented) with time-series models such as the ARIMA process and also ARFIMA for robustness. Their forecast performance is compared with the theory-based models using the chosen forecast measures. A generalized specification for ARIMA $(\mathrm{p}, \mathrm{d}, \mathrm{q})$ is given as:

$$
\left(1-\sum_{i=1}^{p} \rho_{i} L^{i}\right)(1-L)^{d} \pi_{t}=\mu+\left(1-\sum_{i=1}^{q} \phi_{i} L^{i}\right) \varepsilon_{t}
$$

where $\mu$ is the drift parameter, $L$ denotes the lag operator, $p$ and $q$ are the maximum lags for $\pi_{t}$ and $\varepsilon_{t}$, respectively, while $d$ is the order of integration, which can also be defined as the number of times $\pi_{t}$ is differenced to achieve stationarity. In the case of the 
ARFIMA model, however, $(1-L)^{d}$ is described as the fractional differencing operator defined by 9

$$
(1-L)^{d}=\sum_{k=0}^{\infty} \frac{\Gamma(k-d) L^{k}}{\Gamma(-d) \Gamma(k+1)}
$$

where $\Gamma(\cdot)$ denotes the generalized factorial function. The parameter $d$ is allowed to assume any real value. Restricting $d$ to integer values gives rise to the standard ARIMA model. The inflation series $\pi_{t}$ is both stationary and invertible if $\left(1-\sum_{i=1}^{p} \rho_{i} L^{i}\right)$ and $\left(1-\sum_{i=1}^{q} \phi_{i} L^{i}\right)$ lie outside the unit circle and $|d|<0.5$. The process is non-stationary for $d \geq 0.5$ , as it possesses infinite variance (see Granger and Joyeux, 1980).

\section{$4 \quad$ Data and preliminary analysis}

For the purposes of this study, we obtained synchronous time-series data from the US Bureau of Labor Statistics on the following variables: price index of coffee (for all urban US consumers), industrial production, unemployment rates, and headline and core inflation rates. The variables are of the same observation numbers ranging from January 1967 to October 2017, month to month, yielding 610 observations. We begin our preliminary analyses with some summary statistics, and thereafter we subject the series to formal tests, which are preconditions for the LW and WN estimators. As reported in Table 1, average monthly US inflation is approximately $0.33 \%$ for both headline and core inflation. This is quite low, though it must be noted that this is an average of a long time span. The standard deviation values are substantially smaller for core inflation rates than for headline inflation. In the case of monthly growth in output and coffee price, their respective mean values for the period are $0.33 \%$ and $0.18 \%$. The coffee price seems to be the most volatile, even more than the general price level. The statistical distribution of the

\footnotetext{
${ }^{9}$ In a situation where time series exhibit too much long-range dependence to be classified as $\mathrm{I}(0)$ but are not $\mathrm{I}(1)$, the ARFIMA model may be appropriate.
} 
series shows negative skewness for the headline inflation and output series (indicating lower individual values than the average) and positive skewness for both coffee and core inflation (implying higher individual values than the average). The distributions of the variables are platykurtic for all variables.

(Insert Table 1 here)

\subsection{Autocorrelation, conditional heteroskedasticity and unit root properties}

The presence or otherwise of serial correlation is tested using the Ljung-Box Q- and $\mathrm{Q}^{2}$ Statistics test, while Engle's ARCH LM test is employed to test for conditional heteroskedasticity. Table 2 presents the tests at lags 5, 10 and 20 for robustness. The null hypothesis of no conditional heteroskedasticity and serial correlation in the series is rejected for all series. Thus, the results of the test are robust to the varying lag lengths, therefore the issue of autocorrelation and heteroskedasticity should be a concern which has to be resolved in the estimation process.

In line with the standard approach for modeling with time-series data, we also subject each of the inflation variables and the predictor series to ADF and the GARCH-based (Narayan and Liu, 2015) unit root tests. The latter is an extension of the former, as it allows for the GARCH process as well as deterministic trend and structural breaks in the estimation process. As presented in Table 3, the predictors are integrated to order 1, while core and headline inflation are stationary at all levels, although with lower levels of statistical significance. These results are consistent regardless of the choice of unit root tests.

(Insert Table 2 here)

(Insert Table 3 here)

\subsection{Persistence and endogeneity test results}


Given the fact that rejecting the null hypothesis of non-stationarity for the predictor series does not sufficiently justify the absence of persistence, we test for endogeneity and persistence in the predictors. The $\mathrm{AR}(1)$ coefficient estimated for each of the predictors is very close to 1 , suggesting a high degree of persistence in the predictors (see Table 4 ). The extent of endogeneity is also examined. The results, as depicted in Table 4, reveal that the coffee price is endogenous, while output is not in the Phillips curve-based inflation model regardless of the measure for inflation. Moreover, the result of the endogeneity bias test further confirms the strong link between inflation and the coffee price. It also suggests that the demand and supply of coffee are influenced by the stability of the economy, where inflation is prominently used as a proxy. It is important to emphasize that even when we suppress the volatile components of inflation - that is, food and energy prices the conclusion about the presence of endogeneity bias remains unchanged. It is therefore not out of place to consider an alternative estimator, which corrects for any potential bias in the estimation of the proposed APC model for US inflation. Notwithstanding that, the forecast performance of the alternative estimator is compared with other estimators in order to further validate our preference for the former.

\section{(Insert Table 4 here)}

\subsection{Co-movements between coffee price and US inflation}

Prior to a proper discussion of the results, it is necessary to have a cursory look at the series of interest to give us some informal idea of the likely pattern of the relationship. This is achievable with the aid of graphical analyses of the series. The analyses in Figures 1.1 and 1.2 (in levels) as well as Figures 1.3 and 1.4 (in returns) provide brief insights into possible connections between the coffee price and US inflation (whether measured as core or headline inflation) over time. In the absence of a precise co-movement between the series, the coffee price appears to hover around the upward-trending US inflation series. Although the coffee price series has a history of mild spikes here and there, it maintains a steady relationship with the inflation series throughout the review period. Aside from the 
close relationship between coffee price and inflation series evident in the analyses, we can also observe an equal pattern of behavior between headline and core inflation, suggesting that findings emanating from the two measures of inflation will likely be identical.

In addition to the graphical depiction of association between the series, we further investigate the relationship using formal tests, which confirm the possible existence of a long-run relationship between them. Consequently, formal analyses from the bounds test co-integration approach of Pesaran et al. (2001) showed in Table 5 confirm the long-run relationship between coffee price and inflation series. ${ }^{10}$ Thus, taken together with the evidence of co-movement between the series, the co-integration result provides a strong basis for considering the coffee price in the predictive model of US inflation.

(Insert Figures 1)

(Insert Table 5)

\section{$5 \quad$ Discussion of results}

We adopt the TPC and the APC variant to exploit information held on coffee prices to predict US inflation, while accounting for the inherent problems of endogeneity, persistence and conditional heteroskedasticity in the variables and modeling framework. We further compare the results of our theory-based models with time-series models, namely ARIMA and ARFIMA. The analyses are all conducted for both monthly and quarterly data frequencies to pose confidence in the robustness and sensitivity of our results. ${ }^{11} \mathrm{We}$ assess the in-sample and out-of-sample predictability evaluations for the $50 \%$ and $75 \%$ data samples and for 5, 12 and 24 periods ahead of the forecast horizon, specifically for out-of-sample forecast evaluation, using four criteria: RMSE, MAE, C-T and D-M tests. The analyses all stem from the results in Tables 6-14.

\footnotetext{
10 The time-series properties of the variables, being a combination of $\mathrm{I}(0)$ and $\mathrm{I}(1)$, justify the adoption of the bounds test co-integration approach (Pesaran et al., 2001). See Table 5.

11 See the attached supplementary file for the robustness results using quarterly data.
} 


\subsection{In-sample predictability}

Our objective is not to validate the TPC, in which case we would consider how the level of economic activity (measured with the industrial production index [IPI]) could predict inflation. Rather, we are more concerned with the APC, which allows us to assess the role of commodity prices, the coffee price in particular, for forecasting US inflation using both the volatile (headline inflation) and the less volatile measure (core inflation). To answer the research question ("Can the coffee price predict US inflation?") in the affirmative, we require overwhelming evidence of positive and significant values for coffee price coefficients across the measures of inflation (headline and core), data samples (50\% and $75 \%$ ), data frequencies (monthly and quarterly) and estimators (OLS, LW and WN). We turn to information in Table 6 to aid our discussion. The results show that whether we account for endogeneity, persistence and conditional heteroskedasticity or not, the three estimators consistently turn up positive and significant estimates for the coffee price coefficients in the TPC and APC models for the 50\% and 75\% data samples, across monthly and quarterly frequencies, and for both headline and core inflation. We therefore have strong evidence to suggest that the coffee price could serve as a good predictor, along with economic activity, for US inflation. Further confirmation is attempted in the succeeding sections.

\section{(Insert Table 6 here)}

\subsection{In-sample forecast evaluation}

\subsubsection{Does the choice of estimator matter?}

We are still in the dark as to the ideal estimator for our TPC-based and coffee priceinflation predictive models, given the overall evidence of predictability revealed in the previous section. Consequently, we examine the in-sample forecast evaluation for the estimators for the TPC and APC to reveal whether the choice of estimator matters in each of the models; that is, whether accounting for the aforesaid inherent properties improves 
the forecast performance of each of the models. ${ }^{12}$ This helps to show the preferred estimator for the TPC on its own without augmenting for the coffee price, and also for the APC after augmenting the TPC for the coffee price. Subsequently, we make a comparison between the TPC and the APC as to the favored estimator. Further, we decide on the ideal estimator by comparing the estimators of the theoretical models (TPC and APC) and those of the time-series models (ARIMA and ARFIMA). To execute these, we rely on four evaluation criteria: RMSE and MAE (see Tables 7 and 8) and C-T and D-M (see the relevant rows and columns of Tables 9-12). In all, the WN, which incorporates all the statistical properties, is the reference estimator. This information is particularly relevant for the C-T and D-M criteria, which operate on the basis of a predetermined reference estimator.

Conventionally, RMSE and MAE approach zero values, such that the closer the value due to a particular estimator is to zero, the better the forecasting accuracy of that estimator. On the other hand, for the C-T and D-M criteria, a positive C-T statistic and a significant D-M test imply that the reference estimator (WN) outperforms the other estimators in question. For comparison across the TPC model, when we consider a fairly large proportion of the data sample (that is, 75\%), both the RMSE and MAE criteria show that the WN outperforms the LW and OLS for in-sample predictability of US (headline and core) inflation. Interestingly, this result is not sensitive to data frequency, as we arrived at the same conclusion for both monthly and quarterly observed data. The foregoing is further supported by C-T tests, where the results of the $75 \%$ data show that WN outperforms the other estimators. We can therefore confidently affirm for in-sample predictability that the special consideration for the choice of WN estimator matters in predicting US inflation.

(Insert Table 7 here)

(Insert Table 8 here)

12 We hypothesize that if the endogeneity, persistence and conditional heteroskedasticity properties are indeed true, then we expect the WN estimator that incorporates them to outperform the other estimators. 


\subsubsection{TPC vs APC}

Before we compare estimators between the TPC and APC models, it is necessary to confirm the superiority of the WN estimator for the APC model, as for the TPC in the previous section. This facilitates easy comparison of the estimator for the two theoretical models. The findings show overwhelming evidence in favor of the WN estimator for the two data samples for predicting headline and core inflation using monthly data, but only for the more volatile inflation measure (headline inflation) for the data pairs in quarterly frequency. In all, the WN clearly outclasses the ARIMA and ARFIMA models.

Now, to compare the TPC with the APC model involves testing whether the forecast results for the WN estimator in the APC case outperform those of the same estimator in the TPC case. This comparison is done using the C-T test, as shown in Tables 9 and 10, and supported by the D-M test in Tables 11 and 12 . The $\mathrm{C}-\mathrm{T}$ test reveals positive statistical values for the $50 \%$ and $75 \%$ data samples in core and headline inflation. These results indicate that the augmented Phillips curve with the coffee price as a predictor outperforms the traditional variant in the in-sample predictability of US inflation. By implication, we have justified the need to account for the inherent statistical features in the predictor, as well as made a case for the superiority of the WN estimator in the insample predictive model. We therefore have evidence which surpasses the findings of Richards et al. (2012), Chen et al. (2014), Fernandez (2014), Kagraoka (2015), Gelos and Ustyugova (2016) and Karlsson and Karlsson (2016) to uphold the significance of the coffee price, within the family of other commodity prices, as a predictor of consumer inflation.

(Insert Table 9 here)

(Insert Table 10 here)

\subsubsection{Economic model vs statistical model}


Having settled for one of the economic models (i.e. APC), we may be interested in showing explicitly our choice of estimator between the theoretical and statistical models (ARIMA and ARFIMA). It is customary to compare the forecast performance of theoretically motivated predictive models with the statistical models when dealing with financial time-series forecasting such as inflation (see Karlson and Karlson, 2016, for a review on inflation forecasting; see also Atkeson and Ohanian, 2001; Stock and Watson, 2003, 2007, 2008; Ang et al., 2007; and Canova, 2007, for evidence motivating our interest). These studies cast doubt on the efficacy of theoretical inflation models such as the TPC and APC, estimated here for predicting inflation. Remarkably, we have convincing evidence, whether using the RMSE, MAE or C-T test, in favor of the superiority of the WN estimator for the coffee price-Phillips curve augmented model over the two time-series models.

Specifically, the C-T tests for the APC model for forecasting both headline and core inflation show complete dominance of the WN estimator over the ARIMA and ARFIMA statistical models. We therefore have conclusive evidence, first, to augment the TPC with the coffee price for forecasting US inflation given the significance of the coffee market to the economy (see Financial Times, 2017a, b; see also the ncausa.org website); second, to support the conclusions of Westerlund and Narayan $(2012,2015)$ that accounting for the inherent persistence, endogeneity and conditional heteroskedasticity in the coffee price improves the theoretical model's forecast performance; and third, to challenge the position of Stock and Watson's papers that theoretical models can outperform statistical models for forecasting inflation. The implication of these is that a rising coffee price could be an indication of consumer inflation in the USA and, as such, it can be exploited alongside economic activity by the monetary authority to target inflation policy. The foregoing is true for in-sample predictability. Is it also true for out-of-sample inflation predictability? We attempt to answer this question in the next section.

(Insert Table 11 here) 
(Insert Table 12 here)

\subsection{Out-of-sample forecast evaluation}

\subsubsection{Does the choice of estimator matter?}

There seems to be agreement in the literature that good in-sample forecast results do not necessarily equate to good out-of-sample forecast performance. Thus, we consider the out-of-sample forecast performance of the inflation forecast models. We report 6, 12 and 24 periods (month and quarter) ahead of the forecast horizons. Consequently, we evaluate the accuracy of the baseline estimator, the WN, in the TPC and APC models for the outof-sample forecast of headline and core US inflation using RMSE and MAE (see Tables 13 and 14) and the C-T test supported by the D-M results (refer to Tables 9-12).

Starting with the out-of-sample forecast of the TPC, the results of the evaluation criteria corroborate those of the in-sample predictability evaluation that with a fairly large data sample, we find that the unrestricted estimator, $\mathrm{WN}$, supersedes the two other restricted estimators, OLS and LW, with LW being better at $50 \%$ of the data sample. This is consistently so across the three forecast horizons, the two measures of inflation and data frequencies. This is further largely supported by the C-T tests. However, the evidence is too close to call to reveal the better estimator between WN and LW in the APC model (24 out of 48 items of evidence from lower values of RMSE and MAE are in support of WN, excluding instances of equal values). If we deduct the instances of where equal values are recorded, the WN has a slight edge for out-of-sample forecast power over LW in the APC model.

\subsubsection{TPC vs APC}

Although evidence is not unanimous as to the better model for out-of-sample predictability between the LW and NW (note that there is no case for OLS at all), we can convincingly decide between the APC and the TPC for ex post forecast evaluation. With facts supporting the superiority of the APC model (i.e. positive and significant estimates 
of the C-T and D-M tests, respectively), we are backed by evidence to justify augmenting the TPC model with the coffee price. We are also justified in accounting for endogeneity and persistence in the predictor, although modest evidence is available for the relevance of conditional heteroskedasticity in the out-of-sample forecast evaluation.

\subsubsection{Economic model vs statistical model}

Here, we compare estimators between the revealed superior theoretical model, APC, and the time-series (statistical) models, ARIMA and ARFIMA. The RMSE and MSE evaluation criteria consistently turn in higher values for the statistical models compared to the LW and $\mathrm{WN}$ of the APC model. Supporting and conclusive evidence from the harmony of C$\mathrm{T}$ and D-M tests (Tables 9-12) reveals that the APC model consistently outperforms each of the statistical models across the forecast horizons.

(Insert Table 13 here)

(Insert Table 14 here)

\subsection{Robustness and policy implications of findings}

In this study, we adopt a number of sensitivity approaches to establish the robustness of our findings. Thus, we adopt two measures of inflation, headline and core inflation; utilize two inflation forecast models, TPC and APC; conduct analyses over two data samples and frequencies; and employ $50 \%$ and $75 \%$ data samples across monthly and quarterly data frequencies, all using competing estimators: theoretical, OLS, LW and WN, and statistical, ARIMA and ARFIMA. We establish tentative and overwhelming evidence of positive and significant values for in-sample estimation of the inflation model with the coffee price as a major predictor. Remarkably, the result of good out-of-sample predictability, where our augmented theoretical model consistently outperforms the time-series models, is true irrespective of data sample, data frequency and measure of inflation. Thus, our theoretical APC model transcends the statistical models even for out-of-sample inflation forecasting, 
as it supersedes the time-series models for in-sample forecast evaluation. Information contained in this study is particularly relevant for monetary policies for targeting inflation effectively. Thus, a rising coffee price could be a precursor to consumer inflation in the USA and, as such, policy makers can exploit such information alongside economic activity to target either volatile or non-volatile consumer inflation.

Also, we test whether the forecast results of the preferred model, APC, is not sensitive to higher-order moments based on time-varying skewness and kurtosis. For the purpose of this exercise, we consider the GARCH-SK model of Leon et al. (2005) and Narayan and Liu (2018), which is described as the GARCH model with skewness and kurtosis. More specifically, we test whether allowing for time-varying higher-order moments on the Gram-Charlier expansion series will provide better forecast performance than the APC model. The WN-based APC is the best predictive model from our previous analyses and is therefore compared with GARCH-SK. ${ }^{13}$ The $\mathrm{WN}$ approach is chosen here since it is the best estimator among other the competing estimators previously discussed; that is, the LW and OLS estimators. In addition to the standard GARCH model as in Equation (10) and the corresponding conditional variance equation as in Equation (11), the GARCH-SK model requires the provision of additional information on skewness and kurtosis. ${ }^{14}$ The mean equation for inflation can be expressed as:

$$
\pi_{t}=\tau+\sqrt{h_{t} \eta_{t}}
$$

where $\eta_{t} \sim N(0,1), E_{t-1}\left[\eta_{t}\right]=0, E_{t-1}\left[\eta_{t}^{2}\right]=1, E_{t-1}\left[\eta_{t}^{3}\right]=s_{t}$ and $E_{t-1}\left[\eta_{t}^{4}\right]=k_{t}$. The $\pi_{t}$ is the inflation rate; $h_{t}$ is the conditional variance given the information set at $\mathrm{t}$ - 1 period; $\eta_{t}$ is the standard residual term; while the higher-order moments are captured as $s_{t}$

\footnotetext{
${ }^{13}$ The WN (Westerlund and Narayan, 2015) approach that allows for conditional heteroskedasticity, endogeneity and persistence effects in the predictive model of inflation.

${ }^{14}$ We specially thank one of the anonymous reviewers for suggesting this robustness test. Its consideration appears to have strengthened the quality of our paper.
} 
(skewness) and $k_{t}$ (kurtosis). Thus, within the context of GARCH-SK, Equation (10) follows a GARCH process, with higher-order moments represented as:

$$
\begin{aligned}
& h_{t}=\alpha_{0}+\alpha_{1} \varepsilon_{t-1}^{2}+\alpha_{2} h_{t-1} \\
& s_{t}=\beta_{0}+\beta_{1} \varepsilon_{t-1}^{3}+\alpha_{2} s_{t-1} \\
& k_{t}=\gamma_{0}+\gamma_{1} \varepsilon_{t-1}^{4}+\alpha_{2} k_{t-1}
\end{aligned}
$$

Estimation of GARCH-SK involves the maximum likelihood estimator, which requires maximization of the following log-likelihood function:

$$
L_{t}=-\frac{1}{2} h_{t}-\frac{1}{2} \eta_{t}+\ln \left(\psi^{2}\left(\eta_{t}\right)\right)-\ln \left(\Gamma_{t}\right)
$$

where $\psi\left(\eta_{t}\right)=1+\frac{s_{t}}{3 !}\left(\eta_{t}^{3}-3 \eta_{t}\right)+\frac{k_{t}-3}{4 !}\left(\eta_{t}^{4}-6 \eta_{t}^{2}+3\right)$ and $\Gamma_{t}=1+\frac{s_{t}^{2}}{3 !}+\frac{\left(k_{t}-3\right)^{2}}{4 !} .15$

The results for the GARCH-SK model are presented in Table 15 and they cover both insample and out-of-sample forecasts for headline and core inflation rates. For want of space, only the RMSE statistics are presented. We find that the APC model that relies on the WN approach outperforms the GARCH-SK model for both in-sample and out-ofsample forecasts. The results are in fact consistent for both headline and core inflation. Therefore, we can conclude that our proposed APC model is not sensitive to higher-order moments.

(Insert Table 15 here)

\section{$6 \quad$ Concluding remarks}

\footnotetext{
15 See Leon et al. (2005) and Narayan and Liu (2018) for computational details.
} 
This study sets out from impediments established in the extant literature casting doubt on the effectiveness of economic models for forecasting inflation (Atkeson and Ohanian, 2001; Stock and Watson, 2003, 2007, 2008; Ang et al. 2007; Canova, 2007). In a bid to establish the role of the coffee price for forecasting US inflation, we account for inherent statistical properties in the predictors, augment the traditional Phillips curve and find evidence that surpasses findings in the existing literature (e.g. Richards et al., 2012; Chen et al. 2014; Fernandez, 2014; Kagraoka, 2015; Gelos and Ustyugova, 2016; Karlsson and Karlsson, 2016), which upholds the significance of the coffee price, in the family of other commodity prices, as a predictor of consumer inflation. Thus, augmenting the traditional Phillips curve with the coffee price will produce better forecast results for US inflation only when the statistical effects are captured in the estimation process. Put differently, the choice of estimator matters for the predictability of the coffee price in US inflation forecasts. This is a major contribution of this paper to the extant literature involving the role of commodity prices in inflation. Like Chen et al. (2014) and contrary to the findings of Stock and Watson (1999 and others), we show that the proposed augmented Phillips curve outperforms time-series models. Our results are robust to alternative measures of

inflation, different data frequencies, higher-order moments, multiple data samples and multiple forecast horizons.

\section{References}

Ang, A., Bekaert, G. and Wei, M. (2007). Do macro variables, asset markets, or surveys forecast inflation better? Journal of Monetary Economics, 54, 1163-1212.

Atkeson, A. and Ohanian, L. (2001). Are Phillips curves useful for forecasting inflation? Federal Reserve Bank of Minneapolis Quarterly Review, 25, 2-11.

Baillie, R.T. (1989). Commodity prices and aggregate inflation: Would a commodity price rule be worthwhile? Carnegie-Rochester Conference Series on Public Policy, 31, 185-240.

Bannigidadmath, D. and Narayan, P. (2016). Stock return predictability and determinants of predictability and profits. Emerging Markets Review, 26, 153-173. 
Belke, A., Bordon, I.G. and Volz, U. (2012). Effects of global liquidity on commodity and food prices. World Development, 44, 31-43.

Bevan, D., Collier, P. and Gunning, J.W. (1992). Anatomy of a temporary trade shock: The Kenyan coffee boom of 1976-1979. Journal of African Economies, 1, 271-305.

Bloch, H., Dockery, A.M. and Sapsford, D. (2004). Commodity prices, wages, and U.S. inflation in the twentieth century. Journal of Post Keynesian Economics, 26, 523-545.

Blomberg, S.B. and Harris, E.S. (1995). The commodity-consumer price connection: Fact or fable. Economic Policy Review, 2, 21-38.

Bonnell, D., Toensmeyer, U.C., Bacon, J.R. and Perez, A. (1990). Analysis of trends and forecasts in coffee prices and consumer consumption in the Northeast and United States. Journal of Food Distribution Research, vol. 21(1),1-6.

Boughton, J.M. and Branson, W.H. (1988). Commodity prices as a leading indicator of inflation. Cambridge, MA: National Bureau of Economic Research.

Boughton, J.M., Branson, W.H. and Muttardy, A. (1989). Commodity prices and inflation: Evidence from seven large industrial countries. Cambridge, MA: National Bureau of Economic Research.

Browne, F. and Cronin, D. (2010). Commodity prices, money and inflation. Journal of Economics and Business, 62, 331-345.

Campbell, J.Y. and Thompson, S.B. (2008). Predicting excess stock returns out of sample: Can anything beat the historical average? Review of Financial Studies, 21, 1509-1531.

Canova, F. (2007). G-7 inflation forecasts: Random walk, Phillips curve, or what else? Macroeconomic Dynamics, 11, 1-30.

Chen, Y. and Rogoff, K.S. (2003). Commodity currencies. Journal of International Economics, 60, 133-169.

Chen, Y.C., Turnovsky, S.J. and Zivot, E. (2014). Forecasting inflation using commodity price aggregates. Journal of Econometrics, 183, 117-134.

Ciner, C. (2011). Commodity prices and inflation: Testing in the frequency domain. Research in International Business and Finance, 25, 229-237. 
Cody, B.J. and Mills, L.D. (1991). The role of commodity prices in formulating monetary policy. Review of Economics and Statistics, 73, 358-365.

Cuddington, J.T. (1986). Managing commodity export booms: The case of coffee. Country Policy Department Discussion Paper; No. CPD 1986-45. Washington, DC: World Bank.

Davidson, J., Halunga, A., Lloyd, T., McCorriston, S. and Morgan, W. (2016). World commodity prices and domestic retail food price inflation: Some insights from the UK. Journal of Agricultural Economics, 67, 566-583.

Devpura, N., Narayan, P.K. and Sharma, S.S. (2018). Is stock return predictability timevarying? Journal of International Financial Markets, Institutions and Money, 52, 152172.

Economist (2016). Italian coffee firms: Not so espresso. The Economist, 3 March. Available at: https://www.economist.com/business/2016/03/03/not-so-espresso [last accessed 27 December 2018

Edelstein, P. and Kilian, L. (2009). How sensitive are consumer expenditures to retail energy prices? Journal of Monetary Economics, 56, 766-779.

Edwards, S. (1984). Coffee, money and inflation in Colombia. World Development, 12, 11071117.

Euromonitor International (2016). Coffee shops around the world: Three key insights for 2016. Available at: https://blog.euromonitor.com/2016/04/coffee-shops-aroundthe-world-three-key-insights-for-2016.html [last accessed 10 January 2018].

Euromonitor International (2018). Coffee in 2018: The new age of coffee everywhere. Available at: https://go.euromonitor.com/webinar-HotDrinks-2018Coffee_in_2018.html [last accessed 27 December 2018].

Fernandez, V. (2014). Linear and non-linear causality between price indices and commodity prices. Resources Policy, 41, 40-51.

Ferrucci, G., Jiménez-Rodríguez, R. and Onorante, L. (2010). Food price pass-through in the euro area: The role of asymmetries and non-linearities. Working Paper Series No 1168, April. Frankfurt: European Central Bank. 
Financial Times (2017a). Greggs sales rise on coffee, breakfast and salad growth. Financial Times, 1 August. Available at:

https://www.ft.com/content/8d2b384d-e5a2-3ab1-a83c-95a9cbcfe223 [last assessed 15 February 2018]

Financial Times (2017b). Coffee sustainability: The journey from bean to barista laid bare. Financial Times, 24 September. Available at:

https:/ / www.ft.com/content/851f940c-51c6-11e7-a1f2-db19572361bb [last assessed 15 February 2018]

Financial Times (2018) Coca-Cola to buy Costa Coffee chain from Whitbread for $£ 3.9 \mathrm{bn} "$, August 31, 2018. Financial Times. Available at: https:// www.ft.com/content/6782c756-ace3-11e8-89a1-e5de165fa619 [last accessed 17 December 2018]

Frankel, J. (1986). Expectations and commodity price dynamics: The overshooting model. American Journal of Agricultural Economics, 68, 344-348.

Frankel, J.A. (2013). Effects of speculation and interest rates in a carry trade model of commodity prices. NBER Working Paper No. 19463. Cambridge, MA: National Bureau of Economic Research.

Furlong, F. and Ingenito, R. (1996). Commodity prices and inflation. Economic Review. Federal Reserve Bank of San Francisco, 2, 27-47.

Garner, C.A. (1989). Commodity prices: Policy target or information variable? Journal of Money, Credit and Banking, 21, 508-514.

Gassmann, O., Frankenberger, K. and Csik, M. (2014). The business model navigator: 55 models that will revolutionise your business. Harlow: Pearson Education.

Gelos, G. and Ustyugova, Y. (2016). Inflation responses to commodity price shocks - how and why do countries differ? Journal of International Money and Finance, 72, 28-47.

Gilbert, C.L. (1987). International commodity agreements: Design and performance. World Development, 15, 591-616.

Gilbert, C.L. (1990). Primary commodity prices and inflation. Oxford Review of Economic Policy, 6:4, 77-99. 
Gilbert, C.L. (1996). International commodity agreements: An obituary notice. World Development, 24, 1-19.

Gómez, M.I., González, E.R. and Melo, L.F. (2012). Forecasting food inflation in developing countries with inflation targeting regimes. American Journal of Agricultural Economics, 94, 153-173.

Granger, C. W. J. and R. Joyeux (1980). An introduction to long-memory time series models and fractional differencing. Journal of Time Series Analysis 1(1), 15-29.

Hoang, T.H.V., Lahiani, A. and Heller, D. (2016). Is gold a hedge against inflation? New evidence from a nonlinear ARDL approach. Economic Modelling, 54, 54-66.

Hooker, M.A. (2002). Are oil shocks inflationary? Asymmetric and nonlinear specifications versus changes in regime. Journal of Money, Credit and Banking, 34, 540-561.

Kagraoka, Y. (2015). Common dynamic factors in driving commodity prices: Implications of a generalized dynamic factor model. Economic Modelling, 52, 609-617.

Kamas, L. (1986). Dutch disease economics and the Colombian export boom. World Development, 14, 1177-1198.

Karlsson, N. and Karlsson, S. (2016). Forecasting of the inflation rates in Uganda: A comparison of ARIMA, SARIMA and VECM models. Örebro University School of Business.

Kilian, L. (2008). Exogenous oil supply shocks: How big are they and how much do they matter for the US economy? Review of Economics and Statistics, 90, 216-240.

Kyrtsou, C. and Labys, W.C. (2006). Evidence for chaotic dependence between US inflation and commodity prices. Journal of Macroeconomics, 28, 256-266.

Lenten, L.J. (2010). Bananas and petrol: Further evidence on the forecasting accuracy of the ABS 'headline' and 'underlying' rates of inflation. Journal of Forecasting, 29, 556-572.

Leon, A., Rubio, G. and Serna, G. (2005). Autoregressive conditional volatility, skewness and kurtosis. Quarterly Review of Economics and Finance, 45, 599-618. 
Lewellen, J. (2004). Predicting returns with financial ratios. Journal of Financial Economics, 74, 209-235.

Mahdavi, S. and Zhou, S. (1997.) Gold and commodity prices as leading indicators of inflation: Tests of long-run relationship and predictive performance. Journal of Economics and Business, 49, 475-489.

Maizels, A., Bacon, R.W. and Mavrotas, G. (1997). Commodity supply management by producing countries: A case-study of the tropical beverage crops. Oxford: Oxford University Press.

Makin, A.J., Narayan, P.K. and Narayan, S. (2014). What expenditure does Anglosphere foreign borrowing fund? Journal of International Money and Finance, 40, 63-78.

Malliaris, A.G. (2006). US inflation and commodity prices: Analytical and empirical issues. Journal of Macroeconomics, 28, 267-271.

Marquis, M.H. and Cunningham, S.R. (1990). Is there a role for commodity prices in the design of monetary policy? Some empirical evidence. Southern Economic Journal, 57, 394-412.

Ministry of Agriculture and Agri-Food Canada (2013). Coffee in the United States: Sustainability trends. Market Indicator Report, Ottawa, ON: International Market Bureau, February.

Mintel (2012). Coffee - US. October. London: Mintel Group.

Musonda, F.M. and Luvanda, E. (1986). The consequences of the 1976-1977 coffee booms on the Tanzanian economy: A test of the Dutch disease model. East Africa Economic Review, 7(2), 1-16.

Narayan, P.K. and Bannigidadmath, D. (2015). Are Indian stock returns predictable? Journal of Banking \& Finance, 58, 506-531.

Narayan, P.K. and Gupta, R. (2015). Has oil price predicted stock returns for over a century? Energy Economics, 48, 18-23.

Narayan, P.K. and Liu, R. (2011). Are shocks to commodity prices persistent? Applied Energy, 88, 409-416. 
Narayan, P.K. and Liu, R. (2015). A unit root model for trending time-series energy variables. Energy Economics, 50, 391-402

Narayan, P.K. and Liu, R. (2018). A new GARCH model with higher moments for stock return predictability. Journal of International Financial Markets, Institutions and Money, 56, 93-103.

Narayan, P.K. and Sharma, S.S. (2014). Firm return volatility and economic gains: The role of oil prices. Economic Modelling, 38, 142-151.

Narayan, P.K. and Sharma, S.S. (2018). An analysis of time-varying commodity market price discovery. International Review of Financial Analysis, 57, 122-133.

Navamuel, L.E., Vázquez, F.E. and Morollón, R.F. (2017). Higher cost of living in urban areas? An AIDS-based analysis of food in Spain. Regional Studies, 51, 1665-1677.

Orphanides, A. and van Norden, S. (2004). The reliability of inflation forecast based on output gap estimates in real time. Journal of Money, Credit, and Banking, 37, 583-600.

Otero, J.G. (2001.) Coffee export booms and monetary disequilibrium: Some evidence for Columbia. Applied Economics, 33, 267-276.

Peach, R., Rich, R. and Linder, M. H. (2013). The parts are more than the whole: Separating goods and services to predict core inflation. Federal Reserve Bank of New York Current Issues in Economics and Finance, 19(7), 1-8.

Pecchenino, R.A. (1992). Commodity prices and the CPI: Cointegration, information and signal extraction. International Journal of Forecasting, 7, 493-500.

Pesaran M.H., Shin Y. and Smith R.J. (2001). Bounds testing approaches to the analysis of level relationships. Journal of Applied Econonics, 16, 289-326.

Phan, D.H.B., Sharma, S.S. and Narayan, P.K. (2015). Stock return forecasting: Some new evidence. International Review of Financial Analysis, 40, 38-51.

Raju, S.S. and Melo, A. (2003). Money, real output, and deficit effects of coffee booms in Colombia. Journal of Policy Modelling, 25, 963-983.

Richards, T.J., Allender, W.J. and Hamilton, S.F. (2012). Commodity price inflation, retail pass-through and market power. International Journal of Industrial Organization, 30, $50-57$. 
Richards, T.J. and Pofahl, G.M. (2009). Commodity prices and food inflation. American Journal of Agricultural Economics, 91, 1450-1455.

Riggi, M. and Venditti, F. (2015). Failing to forecast low inflation and Phillips curve instability: A euro area perspective. International Finance, 18, 47-67.

Salisu A.A, Ademuyiwa, I. and Isah, K. (2018). Revisiting the forecasting accuracy of Phillips curve: The role of oil price. Energy Economics, 70, 334-356

Salisu, A.A. and Isah, K.O. (2018). Predicting US inflation: Evidence from a new approach. Economic Modelling, 71, 134-158..

Salisu, A.A., Isah, K. and Ademuyiwa, I. (2017a). Testing for asymmetries in the predictive model of oil-inflation. Economics Bulletin, 37, 1797-1804.

Salisu, A.A., Isah O.K., Oyewole, J.O. and Akanni, O.L. (2017b). Modelling oil priceinflation nexus: The role of asymmetries. Energy, 125, 97-106.

Sek, S.K. (2017). Impact of oil price changes on domestic price inflation at disaggregated levels: Evidence from linear and nonlinear ARDL modeling. Energy, 130, 204-217

Sephton, P.S. (1991). Comment on Garner: Commodity prices: Policy target or information variable? Journal of Money, Credit and Banking, 23, 260-266.

Stock, J.H. and Watson, M.W. (1999). Forecasting inflation. Journal of Monetary Economics, 44, 293-335.

Stock, J. H. and M. W Watson (2003). "Forecasting output and inflation: The role of asset prices." Journal of Economic Literature 41(3): 788-829.

Stock, J.H. and Watson, M.W. (2007). Why has U.S. inflation become harder to forecast? Journal of Money, Credit, and Banking, 39, 3-34.

Stock, J.H. and Watson, M.W. (2008). Phillips curve inflation forecast. NBER Working Paper 14322. Cambridge, MA: National Bureau of Economic Research.

Stock, J.H. and Watson, M.W. (2009). Modelling inflation after the crisis. NBER Working Paper No. 16488, Cambridge, MA: National Bureau of Economic Research.

Swaray, R. (2007). How did the demise of international commodity agreements affect volatility of primary commodity prices? Applied Economics, 39, 2253-2260.

Tallman, E.W. and Zaman, S. (2017). Forecasting inflation: Phillips curve effects on services price measures. International Journal of Forecasting, 33, 442-457. 
US Department of Agriculture (2017). Coffee: World markets and trade. Foreign Agricultural Service, December. Available at:

https://apps.fas.usda.gov/psdonline/circulars/coffee.pdf [last accessed 6 January 2019].

Valcarcel, V.J. and Wohar, M.E. (2013). Changes in the oil price-inflation pass-through. Journal of Economics and Business, 68, 24-42.

Webb, R.H. (1988). Commodity prices as predictors of aggregate price change. Economic Review, Federal Reserve Bank of Richmond, November Issue, 3-11.

Westerlund, J. and Narayan, P.K. (2012). Does the choice of estimator matter when forecasting returns? Journal of Banking and Finance, 36, 2632-2640.

Westerlund, J. and Narayan, P.K. (2015). Testing for predictability in conditionally hetoroscedasticity stock returns. Journal of Financial Econometrics, 13, 342-375. 


\section{Figures}
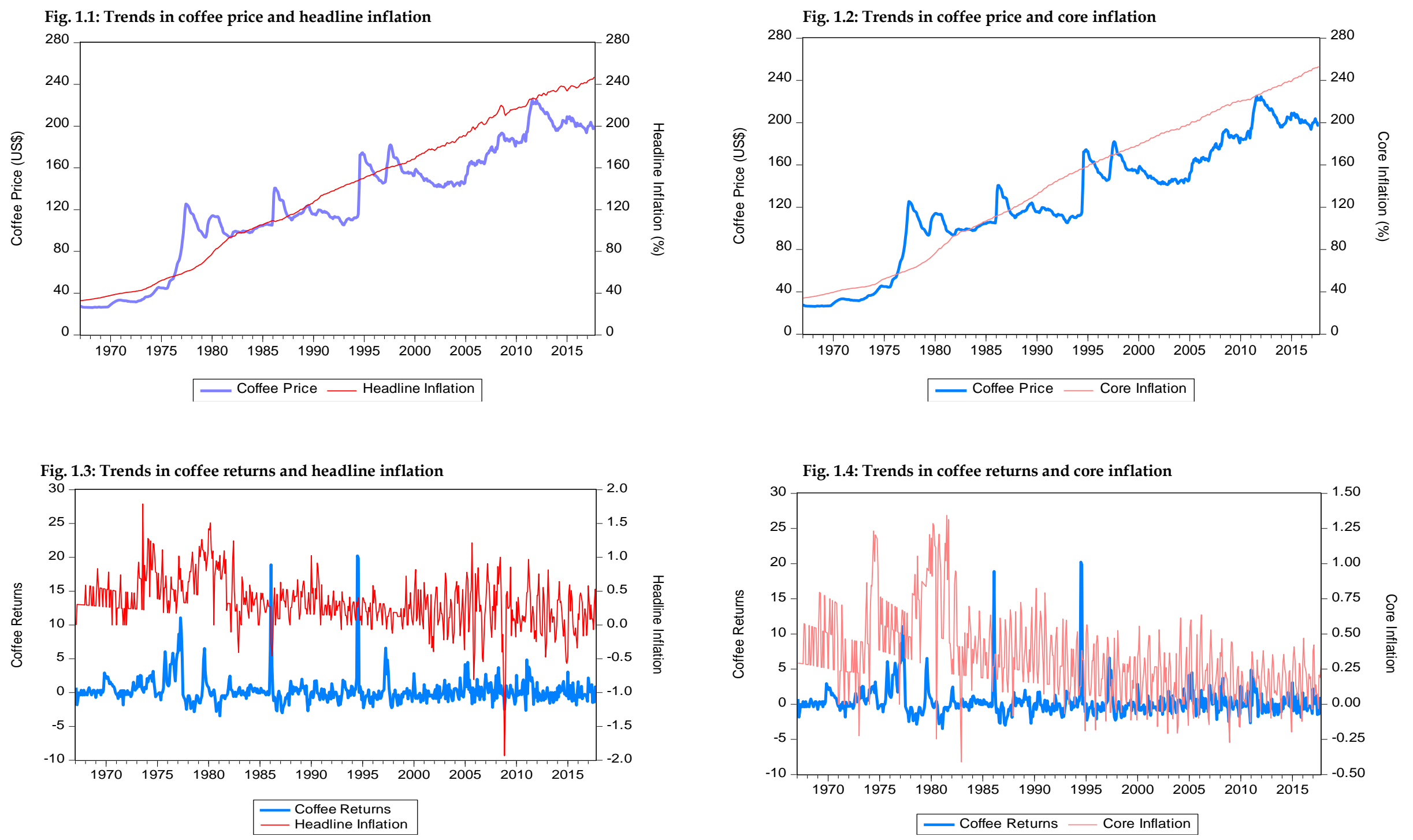
Table 1: Summary Statistics

\begin{tabular}{lllll}
\hline Variables & Mean & Std. Dev. & Skewness & Kurtosis \\
\hline$p_{t}^{*}$ & 0.3261 & 2.1187 & 4.1854 & 37.9866 \\
$y_{t}^{*}$ & 0.1758 & 0.7300 & -1.1095 & 8.2862 \\
$\pi_{t}^{* h}$ & 0.3307 & 0.3649 & -0.1303 & 6.3061 \\
$\pi_{t}^{* c}$ & 0.3294 & 0.2882 & 0.8480 & 4.0354 \\
\hline
\end{tabular}

Note: $p_{t}^{*}, y_{t}^{*}, \pi_{t}^{* h}$ and $\pi_{t}^{* c}$ are month-on-month growth rates of coffee price, output, headline CPI and core CPI respectively.

Table 2: Autocorrelation and Conditional Heteroscedasticity Tests

\begin{tabular}{|c|c|c|c|c|}
\hline \multirow[t]{2}{*}{ Lag Struct. } & \multirow[t]{2}{*}{ Variables } & \multicolumn{2}{|c|}{ Serial Correlation Test } & \multirow{2}{*}{$\begin{array}{l}\text { Heteroscedasticity Test } \\
\mathrm{ARCH}\end{array}$} \\
\hline & & Q-Stat & $\mathrm{Q}^{2}$-Stat & \\
\hline \multirow{4}{*}{ (5) } & $p_{t}$ & $2960.7199 * * *$ & $2937.9291 * * *$ & $183207.0690 * * *$ \\
\hline & $y_{t}$ & $2990.4557 * * *$ & 2872.0017 *** & $42610.6203 * * *$ \\
\hline & $\pi_{t}^{h}$ & $2986.2035 * * *$ & 2927.9234 *** & $1377803.3492 * * *$ \\
\hline & $\pi_{t}^{c}$ & $2987.7890 * * *$ & 2924.3536 *** & $2649530.7125^{* * *}$ \\
\hline \multirow{4}{*}{ (10) } & $p_{t}$ & $5726.5183 * * *$ & 5627.7935 *** & 84559.1842 *** \\
\hline & $y_{t}$ & $5853.2083 * * *$ & $5355.5455 * * *$ & $20666.6651 * * *$ \\
\hline & $\pi_{t}^{h}$ & $5848.4526 * * *$ & $5633.4375 * * *$ & $657878.6687 * * *$ \\
\hline & $\pi_{t}^{c}$ & $5854.3449 * * *$ & 5621.6766 *** & $1437742.4376^{* * *}$ \\
\hline \multirow{4}{*}{ (20) } & $p_{t}$ & $10656.4538^{* * *}$ & 10196.1779 *** & 36193.5073 *** \\
\hline & $y_{t}$ & 11208.2216 *** & 9299.4912 *** & $9234.6937 * * *$ \\
\hline & $\pi_{t}^{h}$ & $11198.6748^{* * *}$ & $10380.1309 * * *$ & $302081.0317^{* * *}$ \\
\hline & $\pi_{t}^{c}$ & 11222.7405 *** & 10349.7451 *** & 744639.8613 *** \\
\hline
\end{tabular}

Note: $p_{t}, y_{t}, \pi_{t}^{h}$ and $\pi_{t}^{c}$ denote the coffee price, output, headline CPI and core CPI respectively, all expressed in natural logarithm. ${ }^{* * *}$ represents significance at $1 \%$ given that all the estimated F-statistics of the ARCH effects for heteroscedasticity tests and the Ljung Box Q- \& $\mathrm{Q}^{2}$-statistics for autocorrelation tests are significant at $1 \%$. The tests are conducted at different lag lengths, 5, 10 and 20 for robustness. This indicates the rejection of the null of no serial correlation and no conditional heteroscedasticity at all lags at the specified significance level. 
Table 3: Unit root tests

\begin{tabular}{lllll}
\hline & \multicolumn{2}{c}{ ADF Test } & \multicolumn{2}{c}{ NL (2015) Test } \\
\hline Variables & T-test $(k)$ & $\mathrm{I}(\mathrm{d})$ & T-statistic & $\mathrm{I}(\mathrm{d})$ \\
$p_{t}$ & $-9.5743^{* * *}(2)$ & $\mathrm{I}(\mathrm{I})$ & $-2.2389^{* * *}$ & $\mathrm{I}(1)$ \\
$y_{t}$ & $-7.9219^{* * *}(4)$ & $\mathrm{I}(\mathrm{I})$ & $-2.33830^{* *}$ & $\mathrm{I}(1)$ \\
$\pi_{t}^{h}$ & $-2.8336^{*}(12)$ & $\mathrm{I}(0)$ & $-1.852377^{*}$ & $\mathrm{I}(0)$ \\
$\pi_{t}^{c}$ & $-2.9554^{* *}(14)$ & $\mathrm{I}(0)$ & $-5.8037^{* * *}$ & $\mathrm{I}(0)$ \\
\hline
\end{tabular}

Note: $p_{t}, y_{t}, \pi_{t}^{h}$ and $\pi_{t}^{c}$ denote the coffee price, output, headline CPI and core CPI respectively, all expressed in natural logarithm. $k$ represents the optimal lag for the ADF test selected using the Akaike Information Criterion (AIC), and ${ }^{* * * * *}$ and $*$ indicate $1 \%, 5 \%$ and $10 \%$ levels of significance respectively. We complement the ADF test with the NL (2015), Narayan and Liu (2015) GARCH-based unit root test based on the underlying test equation $\Delta y_{t}-\alpha_{0}+\alpha_{1} t+\delta y_{t-1}+\sum_{i=1}^{k} \phi_{i} \beta_{i t}+\varepsilon_{t}$ where $y_{t}$ denotes the series of concern, $\mathrm{t}$ is the time trend, $\beta_{i t}-1$ if $t \geq$ the the break date, and zero otherwise. The null hypothesis of NL unit root given as $\delta=0$ is tested against the alternative hypothesis of stationarity denoted as $\delta<0$.

\section{Table 4: Persistence and endogeneity test results}

\begin{tabular}{llll}
\hline Variable & Persistence & \multicolumn{2}{c}{ Endogeneity } \\
\cline { 3 - 3 } & & $\pi_{t}^{h}$ & $\pi_{t}^{c}$ \\
$p_{t}$ & $0.9961^{* * *}$ & $-1.0736^{* * *}$ & $-1.1561^{* * *}$ \\
$y_{t}$ & $0.9985^{* * *}$ & -1.2331 & -0.7824 \\
\hline
\end{tabular}

Note: The test equation for persistence follows the first autoregressive process $\left(z_{t}=\omega+\rho z_{t-1}+e_{t}\right)$ where $z_{t}$ is a potential predictor. The endogeneity test is obtained by regressing the residual term from the original predictive model (i.e. $\pi_{t}=\mu+\beta z_{t-1}+v_{t}$ ) on the residuals from the persistence equation $\left(\hat{e}_{t}\right)$. Thus, the endogeneity test equation is given as $\hat{v}_{t}=\gamma \hat{e}_{t}+\varepsilon_{t}$ with the null hypothesis of no endogeneity effect. ${ }^{* *}$ represents significance at $1 \%$ at which the coefficients of the persistence and endogeneity effects are statistically significant.

Table 5: Bounds test cointegration

\begin{tabular}{lcccc}
\hline Null hypothesis & F-statistics & $\mathbf{I}(\mathbf{0})$ bound & I(1) bound & Decision \\
\hline $\begin{array}{l}\text { No long run relationship } \\
\text { between } p_{t} \text { and } \pi_{t}^{h}\end{array}$ & 22.67774 & 6.84 & 7.84 & Reject the null \\
$\begin{array}{l}\text { No long run relationship } \\
\text { between } p_{t} \text { and } \pi_{t}^{c}\end{array}$ & 42.88977 & 6.84 & 7.84 & Reject the null \\
\hline
\end{tabular}

Note: $p_{t}, \pi_{t}^{h}$ and $\pi_{t}^{c}$ denote the coffee price, headline CPI and core CPI respectively, all expressed in natural logarithm. We reject the null if the F statistic is greater than the $\mathrm{I}(1)$ bound critical value. The $\mathrm{I}(0)$ and $\mathrm{I}(1)$ bound critical values are as provided in Pesaran et al. (2001) designed for bounds test cointegration. 
Table 6: Predictability Results for US Inflation

\begin{tabular}{|c|c|c|c|c|c|c|c|c|c|c|c|c|}
\hline & \multicolumn{6}{|c|}{ HEADLINE INFLATION } & \multicolumn{6}{|c|}{ CORE INFLATION } \\
\hline & \multicolumn{3}{|c|}{$50 \%$} & \multicolumn{3}{|c|}{$75 \%$} & \multicolumn{3}{|c|}{$50 \%$} & \multicolumn{3}{|c|}{$75 \%$} \\
\hline & OLS & LW & WN & OLS & LW & WN & OLS & LW & WN & OLS & LW & WN \\
\hline \multicolumn{13}{|c|}{ Traditional Phillips Curve } \\
\hline$y_{t}$ & $\begin{array}{l}2.5517^{* * *} \\
(0.0476)\end{array}$ & $\begin{array}{l}0.0220^{* * *} \\
(0.0034)\end{array}$ & $\begin{array}{l}0.0205^{*+*+} \\
(0.0034)\end{array}$ & $\begin{array}{l}1.7849^{\text {tht }} \\
(0.0301)\end{array}$ & $\begin{array}{c}0.0003 \\
(0.0015)\end{array}$ & $\begin{array}{c}0.0003 \\
(0.0014)\end{array}$ & $\begin{array}{l}2.5305^{+* * x} \\
(0.0464)\end{array}$ & $\begin{array}{l}0.0151^{* * *} \\
(0.0031)\end{array}$ & $\begin{array}{l}0.0146^{\text {tht }} \\
(0.0032)\end{array}$ & $\begin{array}{l}1.8226^{* * *} \\
(0.0291)\end{array}$ & $\begin{array}{l}-0.0026^{*} \\
(0.0014)\end{array}$ & $\begin{array}{c}-0.0027^{* *} \\
(0.0013)\end{array}$ \\
\hline \multicolumn{13}{|c|}{ Augmented Phillips Curve } \\
\hline$y_{t}$ & $\begin{array}{l}1.7122^{2 *+*} \\
(0.0947)\end{array}$ & $\begin{array}{l}0.0188^{*+*} \\
(0.0033)\end{array}$ & $\begin{array}{l}0.0177^{\text {*t+k}} \\
(0.0033)\end{array}$ & $\begin{array}{l}1.0198^{\text {t*kt }} \\
(0.0394)\end{array}$ & $\begin{array}{l}0.0023^{*} \\
(0.0014)\end{array}$ & $\begin{array}{c}0.0019 \\
(0.0013)\end{array}$ & $\begin{array}{l}1.8628^{* * * x} \\
(0.0972)\end{array}$ & $\begin{array}{l}0.0106^{* * *} \\
(0.0031)\end{array}$ & $\begin{array}{l}0.0106^{\text {*t*k }} \\
(0.0031)\end{array}$ & $\begin{array}{l}1.1318^{\star * * *} \\
(0.0408)\end{array}$ & $\begin{array}{l}-0.0008 \\
(0.0013)\end{array}$ & $\begin{array}{l}-0.0012 \\
(0.0012)\end{array}$ \\
\hline$p_{t}$ & $\begin{array}{l}0.2752^{2 *+*} \\
(0.0279)\end{array}$ & $\begin{array}{l}0.0042^{*+* k} \\
(0.0008)\end{array}$ & $\begin{array}{l}0.0044^{* * * *} \\
(0.0008)\end{array}$ & $\begin{array}{l}0.4375^{*+* t} \\
(0.0192)\end{array}$ & $\begin{array}{l}0.0048^{\text {*t*x }} \\
(0.0006)\end{array}$ & $\begin{array}{l}0.0044^{* * *} \\
(0.0007)\end{array}$ & $\begin{array}{l}0.2189^{* * *} \\
(0.02867)\end{array}$ & $\begin{array}{l}0.0040^{* * *} \\
(0.0007)\end{array}$ & $\begin{array}{l}0.0041^{\text {t*t }} \\
(0.0007)\end{array}$ & $\begin{array}{l}0.3951^{* *+*} \\
(0.0199)\end{array}$ & $\begin{array}{l}0.0046^{* * *} \\
(0.0005)\end{array}$ & $\begin{array}{l}0.0044^{* * *} \\
(0.0005)\end{array}$ \\
\hline
\end{tabular}

Note: The in-sample predictability in a single-factor case is obtained by estimating the equation $\pi_{t}=\alpha+\beta z_{t-1}+\gamma\left(z_{t}-\rho z_{t-1}\right)+\varepsilon_{t}$ where $\hat{\beta}$ denotes the

coefficient on the predictor $z_{t-1}$. For a multi-factor case, the given equation is extended to capture as many terms of $\beta z_{t-1}$ and $\gamma\left(z_{t}-\rho z_{t-1}\right)$ as the number of additional predictors being included in the predictive model. The competing estimators explored for the in-sample predictability are the ordinary least squares (OLS), Lewellen (LW), and Westerlund and Narayan (WN) estimators applied to the $50 \%$ and $75 \%$ of the data for forecasting headline and core inflation. The values reported in parentheses are standard errors while ${ }^{* * *},{ }^{* *}$ and * denote $1 \%, 5 \%$ and $10 \%$ levels of significance respectively. The null hypothesis of no predictability is rejected if there is statistical significance at least at $10 \%$ significance level. 
Table 7: In-Sample Forecast Performance using Root Mean Square Error

\begin{tabular}{lccccccccc}
\hline & \multicolumn{3}{c}{ Augmented Phillips Curve } & \multicolumn{3}{c}{ Traditional Phillips Curve } & \multicolumn{2}{c}{ Time Series Model } \\
\cline { 2 - 9 } & OLS & LW & WN & OLS & LW & WN & ARIMA & ARFIMA \\
\hline $\begin{array}{l}\text { Headline Inflation } \\
\text { 50\% Sample }\end{array}$ & 0.1243 & 0.0368 & 0.0362 & 0.1431 & 0.0634 & 0.0640 & 0.0633 & 0.0691 \\
75\% Sample & 0.1274 & 0.0388 & 0.0391 & 0.1866 & 0.0779 & 0.0728 & 0.0575 & 0.1116 \\
$\begin{array}{l}\text { Core Inflation } \\
\text { 50\% Sample }\end{array}$ & & & & & & & & \\
75\% Sample & 0.1277 & 0.0259 & 0.0256 & 0.1396 & 0.0543 & 0.0550 & 0.0603 & 0.0773 \\
\hline
\end{tabular}

Note: The reported RMSE are for comparing the single factor (TPC) and multi-factor (APC) predictive models as well as the time series models across the various estimators. The forecast performances are conducted for half and three-quarter of the data (50\% and $75 \%$ ) for in-sample predictability of headline and core inflation. Zero RMSE indicates perfect predictability of the different inflation measures; hence, the closer the RMSE to zero, the better the predictability.

Table 8: In-Sample Forecast Sample using Mean Absolute Error

\begin{tabular}{lccccccccc}
\hline & \multicolumn{2}{c}{ Augmented Phillips Curve } & \multicolumn{2}{c}{ Traditional Phillips Curve } & \multicolumn{2}{c}{ Time Series Model } \\
\cline { 2 - 10 } & OLS & LW & WN & OLS & LW & WN & ARIMA & ARFIMA \\
\hline Headline Inflation & & & & & & & & \\
50\% Sample & 0.0951 & 0.0296 & 0.0295 & 0.1148 & 0.0489 & 0.0526 & 0.0525 & 0.0581 \\
75\% Sample & 0.0941 & 0.0324 & 0.0316 & 0.1687 & 0.0676 & 0.0602 & 0.0462 & 0.0964 \\
Core Inflation & & & & & & & & \\
50\% Sample & 0.0991 & 0.0199 & 0.0198 & 0.1112 & 0.0433 & 0.0462 & 0.0516 & 0.0666 \\
75\% Sample & 0.0999 & 0.0219 & 0.0219 & 0.1635 & 0.0624 & 0.0522 & 0.0682 & 0.0945 \\
\hline
\end{tabular}

Note: The reported MAE are for comparing the single factor (TPC) and multi-factor (APC) predictive models as well as the time series models across the various estimators. The forecast performances are conducted for half and three-quarter of the data (50\% and $75 \%$ ) for in-sample predictability of headline and core inflation. Zero RMSE indicates perfect predictability of the different inflation measures; hence, the closer the MAE to zero, the better the predictability. 


\begin{tabular}{|c|c|c|c|c|c|c|c|c|}
\hline & \multicolumn{4}{|c|}{$50 \%$} & \multicolumn{4}{|c|}{$75 \%$} \\
\hline & \multicolumn{4}{|c|}{ Out-of-Sample } & \multicolumn{4}{|c|}{ Out-of-Sample } \\
\hline & In-Sample & $\mathrm{h}=6$ & $\mathrm{~h}=12$ & $\mathrm{~h}=24$ & In-Sample & $\mathrm{h}=6$ & $\mathrm{~h}=12$ & $\mathrm{~h}=24$ \\
\hline \multicolumn{9}{|c|}{ Augmented Phillips Curve (APC) } \\
\hline ARIMA & 0.4291 & 0.4291 & 0.4291 & 0.4291 & 0.3206 & 0.3205 & 0.3205 & 0.3205 \\
\hline ARFIMA & 0.4764 & 0.4764 & 0.4764 & 0.4764 & 0.6498 & 0.6498 & 0.6498 & 0.6498 \\
\hline $\mathrm{LW}$ & 0.0178 & 0.0178 & 0.0178 & 0.0178 & -0.0060 & -0.0060 & -0.0060 & -0.0060 \\
\hline OLS & 0.7093 & 0.7093 & 0.7093 & 0.7093 & 0.6932 & 0.6932 & 0.6932 & 0.6932 \\
\hline \multicolumn{9}{|c|}{ Traditional Phillips Curve (TPC) } \\
\hline ARIMA & -0.0111 & -0.0111 & -0.0111 & -0.0112 & -0.2657 & -0.2657 & -0.2658 & -0.2658 \\
\hline ARFIMA & 0.0727 & 0.0727 & 0.0727 & 0.0726 & 0.3476 & 0.3476 & 0.3476 & 0.3475 \\
\hline LW & -0.0096 & -0.0096 & -0.0096 & -0.0096 & 0.0657 & 0.0657 & 0.0657 & 0.0657 \\
\hline OLS & 0.5526 & 0.5526 & 0.5527 & 0.5527 & 0.6098 & 0.6099 & 0.6099 & 0.6099 \\
\hline \multicolumn{9}{|c|}{ Traditional Phillips Curve versus Augmented Phillips Curve } \\
\hline $\mathrm{WN}[\mathrm{TPC}]$ & 0.4344 & 0.4353 & 0.4351 & 0.4347 & 0.4629 & 0.4633 & 0.4623 & 0.4626 \\
\hline
\end{tabular}

Note: The predictability results reported are for in-sample and 6-period, 12-period and 24-period ahead out-of-sample forecast horizons for 50\%and 75\% of the sample. For comparison, the benchmark model, WN-based predictive model, is compared with the other listed estimators and models using the Campbell Thompson test. The C-T test is a sign-based test. Positive values indicate superior performance in favour of WN.

Table 10: Campbell-Thompson Test Results for Core Inflation

\begin{tabular}{|c|c|c|c|c|c|c|c|c|}
\hline & \multicolumn{4}{|c|}{$50 \%$} & \multicolumn{4}{|c|}{$75 \%$} \\
\hline & \multicolumn{4}{|c|}{ Out-of-Sample } & \multicolumn{4}{|c|}{ Out-of-Sample } \\
\hline & In-Sample & $h=6$ & $\mathrm{~h}=12$ & $\mathrm{~h}=24$ & In-Sample & $h=6$ & $\mathrm{~h}=12$ & $\mathrm{~h}=24$ \\
\hline \multicolumn{9}{|c|}{ Augmented Phillips Curve (APC) } \\
\hline ARIMA & 0.5753 & 0.5753 & 0.5753 & 0.5752 & 0.6429 & 0.6429 & 0.6429 & 0.6429 \\
\hline ARFIMA & 0.6688 & 0.6688 & 0.6688 & 0.6687 & 0.7407 & 0.7407 & 0.7407 & 0.7407 \\
\hline LW & 0.0118 & 0.0118 & 0.0118 & 0.0118 & -0.0155 & -0.0155 & -0.0155 & -0.0155 \\
\hline OLS & 0.7994 & 0.7994 & 0.7994 & 0.7994 & 0.7937 & 0.7937 & 0.7937 & 0.7937 \\
\hline \multicolumn{9}{|c|}{ Traditional Phillips Curve (TPC) } \\
\hline ARIMA & 0.0884 & 0.0884 & 0.0884 & 0.0883 & 0.1273 & 0.1273 & 0.1273 & 0.1273 \\
\hline ARFIMA & 0.2891 & 0.2891 & 0.289 & 0.289 & 0.3664 & 0.3664 & 0.3664 & 0.3664 \\
\hline $\mathrm{LW}$ & -0.0126 & -0.0126 & -0.0126 & -0.0126 & 0.0522 & 0.0522 & 0.0522 & 0.0522 \\
\hline OLS & 0.6061 & 0.6061 & 0.6061 & 0.6062 & 0.6317 & 0.6317 & 0.6317 & 0.6317 \\
\hline \multicolumn{9}{|c|}{ Traditional Phillips Curve versus Augmented Phillips Curve } \\
\hline WN [TPC] & 0.5345 & 0.5330 & 0.5331 & 0.5343 & 0.5904 & 0.5909 & 0.5914 & 0.5904 \\
\hline
\end{tabular}

Note: The predictability results reported are for in-sample and 6-period, 12-period and 24-period ahead out-of-sample forecast horizons for 50\%and 75\% of the sample. For comparison, the benchmark model, WN-based predictive model, is compared with the other listed estimators and models using the Campbell Thompson test. The C-T test is a sign-based test. Positive values indicate superior performance in favour of WN. 


$$
50 \%
$$

$75 \%$

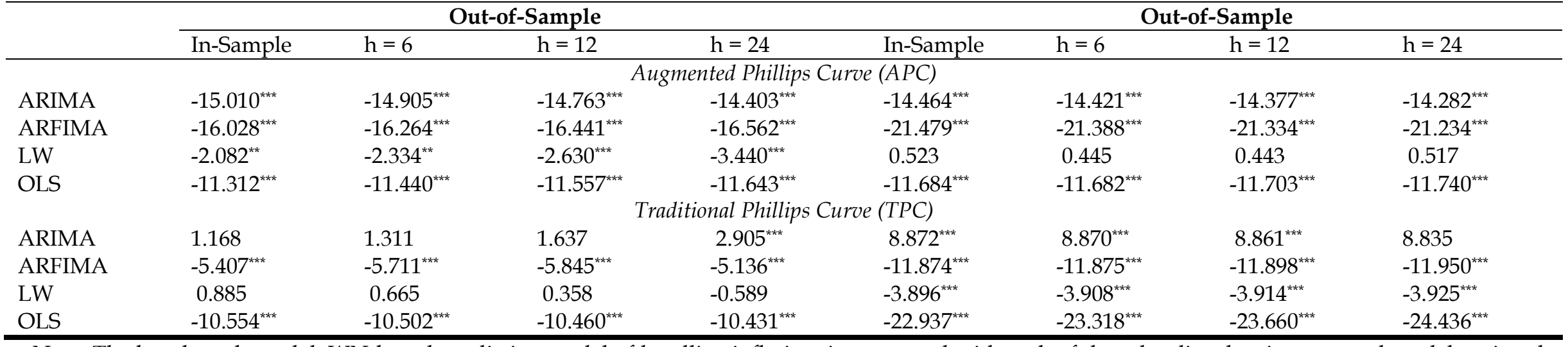

Note: The benchmark model, WN-based predictive model of headline inflation, is compared with each of the other listed estimators and models using the

Diebold-Mariano test. Statistical significance indicates unequal forecast accuracy between two competing models/estimators; otherwise, they are equal. while ${ }^{* * *}, * *$ and * denote $1 \%, 5 \%$ and $10 \%$ levels of significance respectively.

Table 12: Diebold and Mariano Test Result (Core Inflation)

Table 12: Diebold and Mariano Test Result (Core Inflation)

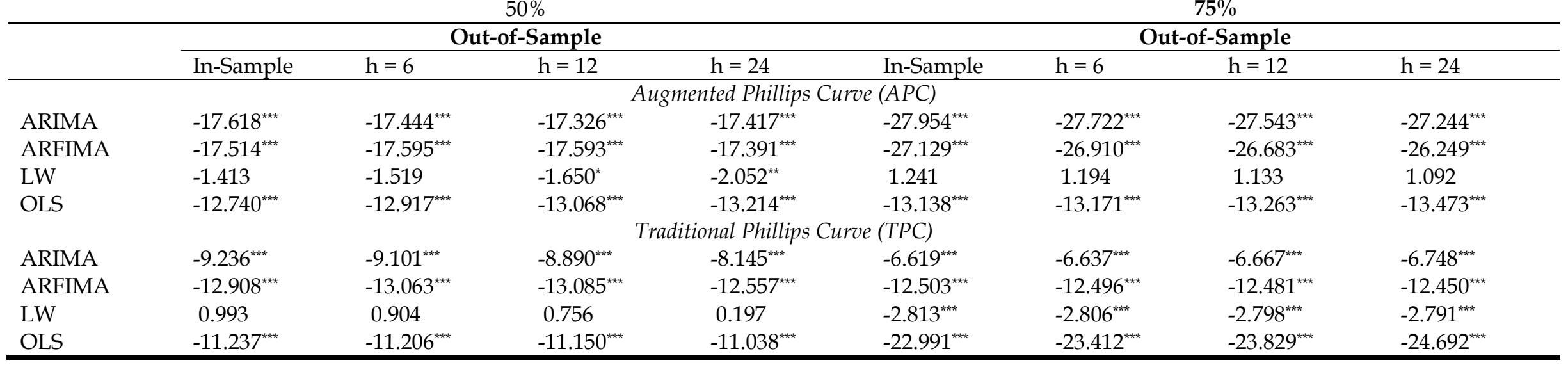

Note: The benchmark model, WN-based predictive model of core inflation, is compared with each of the other listed estimators and models using the

Diebold-Mariano test. Statistical significance indicates unequal forecast accuracy between two competing models/estimators; otherwise, they are equal. while ${ }^{* * *},{ }^{* *}$ and * denote $1 \%, 5 \%$ and $10 \%$ levels of significance respectively. 
Table 13: Out-of-Sample Forecast Performance using Root Mean Square Error

\begin{tabular}{|c|c|c|c|c|c|c|c|c|c|}
\hline & & \multicolumn{3}{|c|}{$\begin{array}{l}\text { Augmented Phillips Curve } \\
\text { (APC) }\end{array}$} & \multicolumn{3}{|c|}{$\begin{array}{c}\text { Traditional Phillips Curve } \\
\text { (TPC) }\end{array}$} & \multicolumn{2}{|c|}{ Time Series Model } \\
\hline & & OLS & LW & WN & OLS & LW & WN & ARIMA & ARFIMA \\
\hline \multicolumn{10}{|l|}{ Headline Inflation } \\
\hline \multirow{3}{*}{$50 \%$ Sample } & $h=6$ & 0.1231 & 0.0364 & 0.0358 & 0.1417 & 0.0628 & 0.0634 & 0.0627 & 0.0684 \\
\hline & $h=12$ & 0.1197 & 0.0354 & 0.0348 & 0.1378 & 0.0610 & 0.0616 & 0.0609 & 0.0664 \\
\hline & $\mathrm{h}=24$ & 0.1219 & 0.0361 & 0.0355 & 0.1404 & 0.0622 & 0.0628 & 0.0621 & 0.0677 \\
\hline \multirow{3}{*}{ 75\% Sample } & $\mathrm{h}=6$ & 0.1265 & 0.0386 & 0.0388 & 0.1854 & 0.0774 & 0.0723 & 0.0571 & 0.1108 \\
\hline & $h=12$ & 0.1257 & 0.0383 & 0.0386 & 0.1842 & 0.0769 & 0.0718 & 0.0568 & 0.1101 \\
\hline & $\mathrm{h}=24$ & 0.1241 & 0.0379 & 0.0381 & 0.1818 & 0.0759 & 0.0709 & 0.0560 & 0.1087 \\
\hline \multicolumn{10}{|l|}{ Core Inflation } \\
\hline \multirow{3}{*}{ 50\% Sample } & $h=6$ & 0.1264 & 0.0257 & 0.0254 & 0.1382 & 0.0538 & 0.0544 & 0.0597 & 0.0766 \\
\hline & $\mathrm{h}=12$ & 0.1229 & 0.0249 & 0.0247 & 0.1343 & 0.0522 & 0.0529 & 0.0580 & 0.0744 \\
\hline & $\mathrm{h}=24$ & 0.1252 & 0.0254 & 0.0251 & 0.1369 & 0.0532 & 0.0539 & 0.0591 & 0.0758 \\
\hline \multirow{3}{*}{ 75\% Sample } & $\mathrm{h}=6$ & 0.1309 & 0.0266 & 0.0270 & 0.1792 & 0.0696 & 0.0660 & 0.0756 & 0.1042 \\
\hline & $\mathrm{h}=12$ & 0.1301 & 0.0264 & 0.0268 & 0.1780 & 0.0692 & 0.0656 & 0.0751 & 0.1035 \\
\hline & $h=24$ & 0.1284 & 0.0261 & 0.0265 & 0.1758 & 0.0683 & 0.0647 & 0.0742 & 0.1022 \\
\hline
\end{tabular}

Note: The reported RMSE are for comparing the single factor (TPC) and multi-factor (APC) predictive models as well as the time series models across the various estimators for the out-of-sample forecast evaluation. The forecast performances are conducted for half and three-quarter of the data (50\% and $75 \%$ ) for 6-, 12- \& 24-months ahead out-of-sample predictability of headline and core inflation. Zero RMSE indicates perfect predictability of the different inflation measures; hence, the closer the RMSE to zero, the better the predictability. 
Table 14: Out-of-Sample Forecast Performance using Mean Absolute Error

\begin{tabular}{|c|c|c|c|c|c|c|c|c|c|}
\hline & & \multicolumn{3}{|c|}{$\begin{array}{l}\text { Augmented Phillips Curve } \\
\text { (APC) }\end{array}$} & \multicolumn{3}{|c|}{$\begin{array}{l}\text { Traditional Phillips Curve } \\
\text { (TPC) }\end{array}$} & \multicolumn{2}{|c|}{ Time Series Model } \\
\hline & & OLS & LW & WN & OLS & LW & WN & ARIMA & ARFIMA \\
\hline \multicolumn{10}{|l|}{ Headline Inflation } \\
\hline \multirow{3}{*}{$50 \%$ Sample } & $h=6$ & 0.0932 & 0.0290 & 0.0289 & 0.1125 & 0.0480 & 0.0516 & 0.0514 & 0.0570 \\
\hline & $h=12$ & 0.0914 & 0.0284 & 0.0284 & 0.1104 & 0.0471 & 0.0506 & 0.0504 & 0.0559 \\
\hline & $h=24$ & 0.0881 & 0.0274 & 0.0273 & 0.1063 & 0.0453 & 0.0487 & 0.0486 & 0.0538 \\
\hline \multirow{3}{*}{ 75\% Sample } & $h=6$ & 0.0929 & 0.0320 & 0.0312 & 0.1665 & 0.0668 & 0.0594 & 0.0456 & 0.0951 \\
\hline & $h=12$ & 0.0917 & 0.0316 & 0.0308 & 0.1644 & 0.0659 & 0.0586 & 0.0450 & 0.0939 \\
\hline & $\mathrm{h}=24$ & 0.0894 & 0.0308 & 0.0301 & 0.1602 & 0.0642 & 0.0571 & 0.0439 & 0.0915 \\
\hline \multicolumn{10}{|l|}{ Core Inflation } \\
\hline \multirow{3}{*}{$50 \%$ Sample } & $h=6$ & 0.0972 & 0.0195 & 0.0194 & 0.1090 & 0.0424 & 0.0453 & 0.0506 & 0.0653 \\
\hline & $h=12$ & 0.0954 & 0.0191 & 0.0190 & 0.1069 & 0.0416 & 0.0444 & 0.0496 & 0.0640 \\
\hline & $\mathrm{h}=24$ & 0.0918 & 0.0184 & 0.0183 & 0.1030 & 0.0401 & 0.0428 & 0.0478 & 0.0616 \\
\hline \multirow{3}{*}{ 75\% Sample } & $\mathrm{h}=6$ & 0.0986 & 0.0217 & 0.0216 & 0.1613 & 0.0616 & 0.0516 & 0.0673 & 0.0933 \\
\hline & $h=12$ & 0.0974 & 0.0214 & 0.0214 & 0.1593 & 0.0608 & 0.0509 & 0.0665 & 0.0920 \\
\hline & $h=24$ & 0.0949 & 0.0208 & 0.0208 & 0.1553 & 0.0593 & 0.0496 & 0.0648 & 0.0897 \\
\hline
\end{tabular}

Note: The reported MAE are for comparing the single factor (TPC) and multi-factor (APC) predictive models as well as the time series models across the various estimators for the out-of-sample forecast evaluation. The forecast performances are conducted for half and three-quarter of the data (50\% and $75 \%)$ for 6 -, 12 \& 24-months ahead out-of-sample predictability of headline and core inflation. Zero RMSE indicates perfect predictability of the different inflation measures; hence, the closer the MAE to zero, the better the predictability. 
Table 15: Forecast results for the WN \& GARCH-SK models using the Root Mean Square Error (RMSE)

\begin{tabular}{|c|c|c|c|c|c|c|}
\hline & \multicolumn{2}{|c|}{ In-Sample } & \multicolumn{4}{|c|}{ Out-of-Sample } \\
\hline & \multirow[t]{2}{*}{ WN-APC } & \multirow{2}{*}{ GARCH-SK } & \multicolumn{2}{|c|}{$\mathbf{W N}$} & \multicolumn{2}{|c|}{ GARCH-SK } \\
\hline & & & $\mathrm{h}=12$ & $\mathrm{~h}=24$ & $\mathrm{~h}=12$ & $h=24$ \\
\hline \multicolumn{7}{|c|}{ Headline Inflation } \\
\hline $50 \%$ Sample & 0.0362 & 5.2824 & 0.0348 & 0.0355 & 5.3095 & 5.3357 \\
\hline 75\% Sample & 0.0391 & 5.5743 & 0.0386 & 0.0381 & 5.5935 & 5.6125 \\
\hline \multicolumn{7}{|c|}{ Core Inflation } \\
\hline $50 \%$ Sample & 0.0256 & 5.3036 & 0.0247 & 0.0251 & 5.3343 & 5.3594 \\
\hline 75\% Sample & 0.0272 & 5.6072 & 0.0268 & 0.0265 & 5.6262 & 5.6449 \\
\hline
\end{tabular}

Note: The Augmented Philips Curve (APC) model is the best predictive model based on the previous analyses and is therefore compared with the GARCH-SK model which is described as the GARCH model with Skewness and Kurtosis. The WN is the Westerlund and Narayan (2015) approach that allows for conditional heterocsedasticity, endogeneity and persistence effects in the predictive model of inflation. The WN approach is chosen here since it is the best estimator among other competing estimators previously discussed, that is, the LW (Lewellen) and the OLS (the Ordinary Least Squares) estimators. The GARCH-SK model is GARCH-based and also allows for higher order moments unlike the WN-based predictive model. The forecast performances are conducted for half and three-quarter of the data $(50 \%$ and $75 \%)$ for in-sample predictability of headline and core inflation. Zero RMSE indicates perfect predictability of the different inflation measures; hence, the closer the RMSE to zero, the better the predictability. 


\section{SUPPLEMENTARY}

\section{RESULTS: QUARTERLY DATA}

Table S1: Predictability Results for US Inflation

\begin{tabular}{|c|c|c|c|c|c|c|c|c|c|c|c|c|}
\hline & \multicolumn{6}{|c|}{ HEADLINE INFLATION } & \multicolumn{6}{|c|}{ CORE INFLATION } \\
\hline & \multicolumn{3}{|c|}{$50 \%$} & \multicolumn{3}{|c|}{$75 \%$} & \multicolumn{3}{|c|}{$50 \%$} & \multicolumn{3}{|c|}{$75 \%$} \\
\hline & OLS & LW & $\mathbf{W N}$ & OLS & LW & WN & OLS & LW & $\mathbf{W N}$ & OLS & $\mathbf{L W}$ & WN \\
\hline \multicolumn{13}{|c|}{ Traditional Phillips Curve } \\
\hline$y_{t}$ & $\begin{array}{l}2.5517^{* * *} \\
(0.0476)\end{array}$ & $\begin{array}{l}0.0220^{* * *} \\
(0.0034)\end{array}$ & $\begin{array}{l}0.0205^{\text {*** }} \\
(0.0034)\end{array}$ & $\begin{array}{l}1.7849^{* * *} \\
(0.0301)\end{array}$ & $\begin{array}{c}0.0003 \\
(0.0015)\end{array}$ & $\begin{array}{c}0.0003 \\
(0.0014)\end{array}$ & $\begin{array}{l}2.5353^{* * *} \\
(0.0800)\end{array}$ & $\begin{array}{l}0.0449^{* * *} \\
(0.0123)\end{array}$ & $\begin{array}{l}0.0432^{* * *} \\
(0.0124)\end{array}$ & $\begin{array}{l}1.8180^{* * *} \\
(0.0503)\end{array}$ & $\begin{array}{l}-0.0082 \\
(0.0052)\end{array}$ & $\begin{array}{l}-0.0085^{*} \\
(0.0046)\end{array}$ \\
\hline \multicolumn{13}{|c|}{ Augmented Phillips Curve } \\
\hline$y_{t}$ & $\begin{array}{l}1.7282^{\star * *} \\
(0.1648)\end{array}$ & $\begin{array}{l}0.0553^{* * *} \\
(0.0122)\end{array}$ & $\begin{array}{c}0.0517^{* * *} \\
(0.0123)\end{array}$ & $\begin{array}{l}1.0185^{* * *} \\
(0.0680)\end{array}$ & $\begin{array}{c}0.0073 \\
(0.0051)\end{array}$ & $\begin{array}{c}0.0057 \\
(0.0047)\end{array}$ & $\begin{array}{l}1.8818^{* * *} \\
(0.1693)\end{array}$ & $\begin{array}{l}0.0300^{* *} \\
(0.0115)\end{array}$ & $\begin{array}{l}0.0299^{* *} \\
(0.0115)\end{array}$ & $\begin{array}{l}1.1290^{* * *} \\
(0.0703)\end{array}$ & $\begin{array}{l}-0.0027 \\
(0.0044)\end{array}$ & $\begin{array}{l}-0.0038 \\
(0.0040)\end{array}$ \\
\hline$p_{t}$ & $\begin{array}{l}0.2716^{* * *} \\
(0.0487)\end{array}$ & $\begin{array}{l}0.0131^{* * *} \\
(0.0029)\end{array}$ & $\begin{array}{l}0.0136^{* * *} \\
(0.0029)\end{array}$ & $\begin{array}{l}0.4383^{* * *} \\
(0.0333)\end{array}$ & $\begin{array}{l}0.0148^{* * *} \\
(0.0023)\end{array}$ & $\begin{array}{l}0.0138^{* * *} \\
(0.0024)\end{array}$ & $\begin{array}{l}0.2145^{* * *} \\
(0.0500)\end{array}$ & $\begin{array}{l}0.0122^{* * *} \\
(0.0025)\end{array}$ & $\begin{array}{l}0.0124^{* * *} \\
(0.0025)\end{array}$ & $\begin{array}{l}0.3962^{* * *} \\
(0.0345)\end{array}$ & $\begin{array}{l}0.0139^{* * *} \\
(0.0018)\end{array}$ & $\begin{array}{l}0.0132^{* * *} \\
(0.0018)\end{array}$ \\
\hline
\end{tabular}

Note: The in-sample predictability in a single-factor case is obtained by estimating the equation $\pi_{t}=\alpha+\beta z_{t-1}+\gamma\left(z_{t}-\rho z_{t-1}\right)+\varepsilon_{t}$ where $\hat{\beta}_{\text {denotes the }}$

coefficient on the predictor $z_{t-1}$. For a multi-factor case, the given equation is extended to capture as many terms of $\beta z_{t-1}$ and $\gamma\left(z_{t}-\rho z_{t-1}\right)$ as the number of additional predictors being included in the predictive model. The values reported in parentheses are standard errors while *** $* *$ and * denote $1 \%, 5 \%$ and $10 \%$ levels of significance respectively. The null hypothesis of no predictability is rejected if there is statistical significance. 
Table S2: In-Sample Forecast Performance using Root Mean Square Error

\begin{tabular}{lcccccccc}
\hline & \multicolumn{2}{c}{ Augmented Phillips Curve } & \multicolumn{2}{c}{ Traditional Phillips Curve } & \multicolumn{2}{c}{ Time Series Model } \\
\cline { 2 - 10 } & OLS & LW & WN & OLS & LW & WN & ARIMA & ARFIMA \\
\hline $\begin{array}{lllllll}\text { Headline Inflation } \\
\text { 50\% Sample }\end{array}$ & 0.1237 & 0.0337 & 0.0331 & 0.1420 & 0.0619 & 0.0626 & 0.0603 & 0.0514 \\
75\% Sample & 0.1267 & 0.0349 & 0.0353 & 0.1863 & 0.0751 & 0.0704 & 0.0531 & 0.0428 \\
Core Inflation & & & & & & & & \\
50\% Sample & 0.1270 & 0.0232 & 0.0231 & 0.1385 & 0.0531 & 0.0539 & 0.0526 & 0.0474 \\
75\% Sample & 0.1312 & 0.0235 & 0.0241 & 0.1801 & 0.0674 & 0.0641 & 0.0551 & 0.0406 \\
\hline
\end{tabular}

Table S3: In-Sample Forecast Sample using Mean Absolute Error

\begin{tabular}{lcccccccc}
\hline & \multicolumn{2}{c}{ Augmented Phillips Curve } & \multicolumn{2}{c}{ Traditional Phillips Curve } & \multicolumn{2}{c}{ Time Series Model } \\
\cline { 2 - 10 } & OLS & LW & WN & OLS & LW & WN & ARIMA & ARFIMA \\
\hline $\begin{array}{l}\text { Headline Inflation } \\
\text { 50\% Sample }\end{array}$ & 0.0947 & 0.0269 & 0.0269 & 0.1138 & 0.0484 & 0.0519 & 0.0504 & 0.0414 \\
75\% Sample & 0.0931 & 0.0289 & 0.0284 & 0.1687 & 0.0656 & 0.0580 & 0.0414 & 0.0359 \\
Core Inflation & & & & & & & & \\
50\% Sample & 0.0988 & 0.0176 & 0.0179 & 0.1106 & 0.0429 & 0.0458 & 0.0432 & 0.0352 \\
75\% Sample & 0.0993 & 0.0188 & 0.0191 & 0.1635 & 0.0603 & 0.0500 & 0.0466 & 0.0262 \\
\hline
\end{tabular}




\begin{tabular}{|c|c|c|c|c|c|c|c|c|}
\hline & \multicolumn{4}{|c|}{$50 \%$} & \multicolumn{4}{|c|}{$75 \%$} \\
\hline & \multicolumn{4}{|c|}{ Out-of-Sample } & \multicolumn{4}{|c|}{ Out-of-Sample } \\
\hline & In-Sample & $h=6$ & $\mathrm{~h}=12$ & $\mathrm{~h}=24$ & In-Sample & $\mathrm{h}=6$ & $\mathrm{~h}=12$ & $\mathrm{~h}=24$ \\
\hline \multicolumn{9}{|c|}{ Augmented Phillips Curve (APC) } \\
\hline ARIMA & 0.4523 & 0.4522 & 0.4522 & 0.4521 & 0.3353 & 0.3353 & 0.3353 & 0.3352 \\
\hline ARFIMA & 0.3573 & 0.3572 & 0.3572 & 0.3570 & 0.1761 & 0.1761 & 0.1760 & 0.1760 \\
\hline $\mathrm{LW}$ & 0.0179 & 0.0179 & 0.0179 & 0.0179 & -0.0098 & -0.0098 & -0.0098 & -0.0098 \\
\hline OLS & 0.7329 & 0.7329 & 0.7329 & 0.7330 & 0.7218 & 0.7218 & 0.7218 & 0.7218 \\
\hline \multicolumn{9}{|c|}{ Traditional Phillips Curve (TPC) } \\
\hline ARIMA & -0.0380 & -0.0382 & -0.0383 & -0.0384 & -0.3268 & -0.3269 & -0.3269 & -0.3270 \\
\hline ARFIMA & -0.2181 & -0.2182 & -0.2183 & -0.2185 & -0.6447 & -0.6447 & -0.6448 & -0.6449 \\
\hline $\mathrm{LW}$ & -0.0122 & -0.0122 & -0.0122 & -0.0122 & 0.0624 & 0.0624 & 0.0624 & 0.0624 \\
\hline OLS & 0.5589 & 0.5590 & 0.5590 & 0.5591 & 0.6222 & 0.6222 & 0.6222 & 0.6223 \\
\hline \multicolumn{9}{|c|}{ Traditional Phillips Curve versus Augmented Phillips Curve } \\
\hline $\mathrm{WN}$ [TPC] & 0.4712 & 0.4725 & 0.4726 & 0.4723 & 0.4986 & 0.4992 & 0.4992 & 0.4985 \\
\hline
\end{tabular}

Note: The benchmark model, WN-based predictive model, is compared with the other listed estimators and models using the Campbell Thompson test. Positive values indicate superior performance in favour of WN.

\section{Table S5: Campbell-Thompson Test Results for Core Inflation}

\begin{tabular}{|c|c|c|c|c|c|c|c|c|}
\hline & \multicolumn{4}{|c|}{$50 \%$} & \multicolumn{4}{|c|}{$75 \%$} \\
\hline & \multicolumn{4}{|c|}{ Out-of-Sample } & \multicolumn{4}{|c|}{ Out-of-Sample } \\
\hline & In-Sample & $\mathrm{h}=6$ & $\mathrm{~h}=12$ & $\mathrm{~h}=24$ & In-Sample & $\mathrm{h}=6$ & $\mathrm{~h}=12$ & $\mathrm{~h}=24$ \\
\hline \multicolumn{9}{|c|}{ Augmented Phillips Curve (APC) } \\
\hline ARIMA & 0.5609 & 0.5608 & 0.5608 & 0.5607 & 0.563 & 0.5629 & 0.5629 & 0.5629 \\
\hline ARFIMA & 0.5124 & 0.5124 & 0.5123 & 0.5123 & 0.4063 & 0.4063 & 0.4063 & 0.4062 \\
\hline $\mathrm{LW}$ & 0.0052 & 0.0052 & 0.0052 & 0.0052 & -0.0261 & -0.0261 & -0.0261 & -0.0261 \\
\hline OLS & 0.8181 & 0.8181 & 0.8181 & 0.8182 & 0.8163 & 0.8163 & 0.8163 & 0.8163 \\
\hline \multicolumn{9}{|c|}{ Traditional Phillips Curve (TPC) } \\
\hline ARIMA & -0.025 & -0.0251 & -0.0252 & -0.0254 & -0.163 & -0.1631 & -0.1631 & -0.1632 \\
\hline ARFIMA & -0.1381 & -0.1382 & -0.1383 & -0.1385 & -0.5799 & -0.58 & -0.58 & -0.5802 \\
\hline $\mathrm{LW}$ & -0.0164 & -0.0164 & -0.0164 & -0.0164 & 0.0484 & 0.0484 & 0.0484 & 0.0484 \\
\hline OLS & 0.6104 & 0.6104 & 0.6105 & 0.6105 & 0.6440 & 0.6440 & 0.6440 & 0.6441 \\
\hline \multicolumn{9}{|c|}{ Traditional Phillips Curve versus Augmented Phillips Curve } \\
\hline WN [TPC] & 0.5714 & 0.5711 & 0.5722 & 0.5708 & 0.6240 & 0.6248 & 0.6240 & 0.6240 \\
\hline
\end{tabular}




\begin{tabular}{|c|c|c|c|c|c|c|c|c|}
\hline & \multicolumn{4}{|c|}{$50 \%$} & \multicolumn{4}{|c|}{$75 \%$} \\
\hline & \multicolumn{4}{|c|}{ Out-of-Sample } & \multicolumn{4}{|c|}{ Out-of-Sample } \\
\hline & In-Sample & $h=6$ & $h=12$ & $\mathrm{~h}=24$ & In-Sample & $h=6$ & $\mathrm{~h}=12$ & $\mathrm{~h}=24$ \\
\hline \multicolumn{9}{|c|}{ Augmented Phillips Curve (APC) } \\
\hline ARIMA & $-8.332^{* * *}$ & $-8.280^{* * *}$ & $-8.220^{* * *}$ & $-8.058^{\star * *}$ & $-7.320^{* * *}$ & $-7.302^{* * *}$ & $-7.289^{* * *}$ & $-7.270^{* * *}$ \\
\hline ARFIMA & $-4.559^{* * *}$ & $-4.550^{* * *}$ & $-4.538^{* * *}$ & $-4.494^{* * *}$ & $-3.432^{* * *}$ & $-3.436^{* * *}$ & $-3.470^{* * *}$ & $-3.620^{* * *}$ \\
\hline LW & -1.166 & -1.303 & -1.454 & $-1.886^{*}$ & 0.491 & 0.467 & 0.483 & 0.564 \\
\hline OLS & $-6.638^{* * *}$ & $-6.704^{* * *}$ & $-6.760^{* * *}$ & $-6.790^{* * *}$ & $-6.882^{* * *}$ & $-6.891^{* * *}$ & $-6.899^{* * *}$ & $-6.918^{\star * *}$ \\
\hline \multicolumn{9}{|c|}{ Traditional Phillips Curve (TPC) } \\
\hline ARIMA & 1.038 & 1.0842 & 1.177 & 1.585 & $8.691^{* * *}$ & $8.668^{* * *}$ & $8.632^{* * *}$ & $8.542^{* * *}$ \\
\hline ARFIMA & $2.434^{* *}$ & $2.462^{* *}$ & $2.515^{* *}$ & $2.749^{* * *}$ & 8.22 & $8.196^{* * *}$ & $8.147^{\star * \star}$ & $7.987^{\star * *}$ \\
\hline LW & 0.639 & 0.505 & 0.322 & -0.24 & $-2.107^{* *}$ & $-2.112^{* *}$ & $-2.114^{* *}$ & $-2.117^{* * *}$ \\
\hline OLS & $-6.057^{* * *}$ & $-6.026^{* * *}$ & $-6.006^{* * *}$ & $-6.011^{* * *}$ & $-13.292^{\star * *}$ & $-13.515^{* * *}$ & $-13.709^{* * *}$ & $-14.151^{* * *}$ \\
\hline
\end{tabular}

Note: The benchmark model, WN-based predictive model, is compared with each of the other listed estimators and models using the Diebold-Mariano test. Statistical significance indicates unequal forecast accuracy between two competing models/estimators; otherwise, they are equal. while ${ }^{* * *}$, ${ }^{* *}$ and ${ }^{*}$ denote $1 \%, 5 \%$ and $10 \%$ levels of significance respectively.

Table S7: Diebold and Mariano Test Result (Core Inflation)

\begin{tabular}{|c|c|c|c|c|c|c|c|c|}
\hline & \multicolumn{4}{|c|}{$50 \%$} & \multicolumn{4}{|c|}{$75 \%$} \\
\hline & \multicolumn{4}{|c|}{ Out-of-Sample } & \multicolumn{4}{|c|}{ Out-of-Sample } \\
\hline & In-Sample & $h=6$ & $\mathrm{~h}=12$ & $\mathrm{~h}=24$ & In-Sample & $h=6$ & $\mathrm{~h}=12$ & $\mathrm{~h}=24$ \\
\hline \multicolumn{9}{|c|}{ Augmented Phillips Curve (APC) } \\
\hline ARIMA & $-8.871^{\star * *}$ & $-8.800^{* * *}$ & $-8.731^{* * *}$ & $-8.627^{\star * *}$ & $-10.609^{* * *}$ & $-10.556^{* * *}$ & $-10.507^{* * *}$ & $-10.407^{\star * *}$ \\
\hline ARFIMA & $-6.949^{* * *}$ & $-6.917^{* * *}$ & $-6.895^{* * *}$ & $-6.915^{* * *}$ & $-5.046^{* * *}$ & $-5.043^{* * *}$ & $-5.041^{* * *}$ & $-5.027^{* * *}$ \\
\hline LW & -0.34 & -0.395 & -0.441 & -0.612 & 1.134 & 1.125 & 1.095 & 1.118 \\
\hline OLS & $-7.405^{\star * *}$ & $-7.495^{* * *}$ & $-7.569^{* * *}$ & $-7.624^{* * *}$ & $-7.641^{* * *}$ & $-7.679^{* * *}$ & $-7.731^{* * *}$ & $-7.848^{* * *}$ \\
\hline \multicolumn{9}{|c|}{ Traditional Phillips Curve (TPC) } \\
\hline ARIMA & 0.934 & 0.971 & 1.045 & 1.418 & $4.028^{* * *}$ & $4.027^{\star * *}$ & $4.030^{* * *}$ & $4.027^{* * *}$ \\
\hline ARFIMA & $2.835^{* * *}$ & $2.860^{* * *}$ & $2.905^{\star * *}$ & $3.139^{* * *}$ & $8.584^{* * *}$ & $8.557^{\star * *}$ & $8.534^{* * *}$ & $8.485^{* * *}$ \\
\hline $\mathrm{LW}$ & 0.726 & 0.671 & 0.588 & 0.267 & -1.492 & -1.489 & -1.485 & -1.482 \\
\hline OLS & $-6.425^{\star * *}$ & $-6.402^{* * *}$ & $-6.370^{* * *}$ & $-6.320^{* * *}$ & $-13.359^{* * *}$ & $-13.606^{* * *}$ & $-13.849^{* * *}$ & $-14.350^{* * *}$ \\
\hline
\end{tabular}

Note: The benchmark model, WN-based predictive model, is compared with each of the other listed estimators and models using the Diebold-Mariano test. Statistical significance indicates unequal forecast accuracy between two competing models/estimators; otherwise, they are equal. while ***,** and * denote $1 \%, 5 \%$ and $10 \%$ levels of significance respectively 
Table S8: Out-of-Sample Forecast Performance using Root Mean Square Error

\begin{tabular}{|c|c|c|c|c|c|c|c|c|c|}
\hline & & \multicolumn{3}{|c|}{ Augmented Phillips Curve } & \multicolumn{3}{|c|}{ Traditional Phillips Curve } & \multicolumn{2}{|c|}{ Time Series Model } \\
\hline & & OLS & LW & WN & OLS & $\mathbf{L W}$ & $\mathbf{W N}$ & ARIMA & ARFIMA \\
\hline \multicolumn{10}{|l|}{ Headline Inflation } \\
\hline \multirow{3}{*}{$50 \%$ Sample } & $h=6$ & 0.1225 & 0.0333 & 0.0327 & 0.1406 & 0.0613 & 0.0620 & 0.0597 & 0.0509 \\
\hline & $\mathrm{h}=12$ & 0.1191 & 0.0324 & 0.0318 & 0.1367 & 0.0595 & 0.0603 & 0.0580 & 0.0495 \\
\hline & $h=24$ & 0.1213 & 0.0330 & 0.0324 & 0.1393 & 0.0607 & 0.0614 & 0.0592 & 0.0504 \\
\hline \multirow{2}{*}{ 75\% Sample } & $h=6$ & 0.1259 & 0.0347 & 0.0350 & 0.1851 & 0.0746 & 0.0699 & 0.0527 & 0.0425 \\
\hline & $\mathrm{h}=24$ & 0.1235 & 0.0340 & 0.0344 & 0.1816 & 0.0732 & 0.0686 & 0.0517 & 0.0417 \\
\hline \multicolumn{10}{|l|}{ Core Inflation } \\
\hline \multirow{3}{*}{$50 \%$ Sample } & $h=6$ & 0.1258 & 0.0230 & 0.0229 & 0.1371 & 0.0526 & 0.0534 & 0.0521 & 0.0469 \\
\hline & $h=12$ & 0.1223 & 0.0224 & 0.0222 & 0.1333 & 0.0511 & 0.0519 & 0.0506 & 0.0456 \\
\hline & $h=24$ & 0.1246 & 0.0228 & 0.0227 & 0.1358 & 0.0520 & 0.0529 & 0.0516 & 0.0465 \\
\hline
\end{tabular}

Table S9: Out-of-Sample Forecast Performance using Mean Absolute Error

\begin{tabular}{|c|c|c|c|c|c|c|c|c|c|}
\hline & & \multicolumn{3}{|c|}{ Augmented Phillips Curve } & \multicolumn{3}{|c|}{ Traditional Phillips Curve } & \multicolumn{2}{|c|}{ Time Series Model } \\
\hline & & OLS & LW & $\mathbf{W N}$ & OLS & LW & $\mathbf{W N}$ & ARIMA & ARFIMA \\
\hline \multicolumn{10}{|l|}{ Headline Inflation } \\
\hline \multirow{3}{*}{ 50\% Sample } & $h=6$ & 0.0929 & 0.0264 & 0.0264 & 0.1116 & 0.0475 & 0.0509 & 0.0494 & 0.0405 \\
\hline & $h=12$ & 0.0911 & 0.0259 & 0.0259 & 0.1095 & 0.0466 & 0.0499 & 0.0484 & 0.0398 \\
\hline & $\mathrm{h}=24$ & 0.0877 & 0.0249 & 0.0249 & 0.1055 & 0.0448 & 0.0481 & 0.0466 & 0.0383 \\
\hline \multirow{2}{*}{ 75\% Sample } & $h=6$ & 0.0919 & 0.0285 & 0.0280 & 0.1665 & 0.0647 & 0.0573 & 0.0408 & 0.0355 \\
\hline & $\mathrm{h}=24$ & 0.0885 & 0.0274 & 0.0269 & 0.1603 & 0.0623 & 0.0551 & 0.0393 & 0.0341 \\
\hline \multicolumn{10}{|l|}{ Core Inflation } \\
\hline \multirow{3}{*}{ 50\% Sample } & $h=6$ & 0.0969 & 0.0173 & 0.0175 & 0.1084 & 0.0421 & 0.0449 & 0.0424 & 0.0345 \\
\hline & $h=12$ & 0.0950 & 0.0169 & 0.0172 & 0.1063 & 0.0413 & 0.0440 & 0.0416 & 0.0338 \\
\hline & $h=24$ & 0.0915 & 0.0163 & 0.0165 & 0.1024 & 0.0397 & 0.0424 & 0.0400 & 0.0326 \\
\hline
\end{tabular}

